\title{
EL NUEVO EMPIRISMO: MUSICOLOGÍA SISTEMÁTICA EN UNA ERA POSTMODERNISTA
}

THE NEW EMPIRICISM: SYSTEMATIC MUSICOLOGY IN A POSTMODERN AGE*

\section{David Huron}

Traducción de Gustavo Yepes

* tercera conferencia de The 1999 Ernest Bloch Lectures 


\section{RESUMEN:}

Se ofrece una panorámica de las corrientes intelectuales en la Filosofía del conocimiento y en la metodología de la investigación, con una retrospectiva que da cuenta de las diferencias que han surgido entre las disciplinas, tales como los métodos comúnmente usados en ciencia, historia o teoría literaria. El postmodernismo y el empirismo científico son descritos y presentados como dos lados de la misma moneda que llamamos escepticismo. Se propone que la elección metodológica para cualquier programa de investigación sea guiada (también) por consideraciones morales y estéticas. Un cuidadoso examen de estos riesgos puede sugerir el uso de un método no ortodoxo, como el cuantitativo en historia o el deconstructivo en ciencia. Se arguye que las herramientas metodológicas (como, por ejemplo, la navaja de Occam) no deberían ser confundidas como puntos de vista filosóficos universales. El artículo aboga por una ampliación de la educación en Metodología, tanto en las artes como en las disciplinas científicas y, en particular, favorece y defiende el uso de metodologías cuantitativas empíricas en varias áreas académicas de la música.

PALABRAS CLAVES: metodología, empirismo, postmodernismo, musicología.

\section{NOTA DEL TRADUCTOR}

Antes de emprender la lectura de este artículo, el lector hispanoparlante debe saber que el Dr. Huron nos ha solicitado advertir lo siguiente: "Este artículo es resultado de una conferencia de 1999 como parte de una serie de ellas, realizada como expositor visitante 'Ernest Bloch' en la Universidad de California en Berkley". Además, el Dr. Huron: a) usa aquí las expresiones 'ciencia' y 'científico' en referencia exclusiva a las ciencias que responden a uno o varios de los calificativos siguientes: básicas, exactas, físicas y naturales. No estoy de acuerdo con restringir así el término pero, obviamente, respetaré el texto, excelente por muchas otras consideraciones. Y b) como explica el autor parcialmente más adelante, en su uso genérico de la palabra 'humanidades' se comprenden también las ciencias sociales y las artes y ciencias para-artísticas (historias de las artes, aspectos filosóficos de las artes, críticas artísticas, musicologías, etc.). 


\section{INTRODUCCIÓN}

Las disciplinas académicas se distinguen unas de otras, principalmente, por sus materias objetos. La musicología difiere de la Química y ésta, de la Ciencia Política, porque cada una de estas disciplinas investiga fenómenos diferentes. Además del objeto de estudio, las disciplinas eruditas también difieren en cómo abordan la investigación. Los métodos del historiador, del científico y del literato divergen dramáticamente. Más aún: dentro de las disciplinas académicas humanísticas, se encuentran comúnmente significativas diferencias metodológicas.

Durante las pasadas dos décadas, la academia musical ha sido influida por, al menos, dos notables movimientos metodológicos. Uno de ellos es el llamado "nueva musicología". Ésta ha sido vagamente guiada por el reconocimiento de los límites del conocimiento humano, la atención al medio social en el que la investigación se realiza y la comprensión de la arena política en la que los productos académicos son utilizados y (aún) abusados. La influencia de la nueva musicología es evidente, primordialmente, en la musicología histórica y en la Etnomusicología recientes, pero también se ha demostrado ampliamente influyente en todas las demás áreas musicales, incluída la educación musical.

Simultáneamente, las pasadas dos décadas han contemplado un aumento en la investigación musical científicamente inspirada. Este nuevo entusiasmo empirista es especialmente evidente en la psicología de la música y en el resurgimiento de la musicología sistemática. Pero el empirismo ha influido también en ciertas áreas de la educación musical y en la investigación de la ejecución interpretativa (performance, añadido por el traductor). Los investigadores musicales inmersos en el trabajo empírico parecen motivados por el renovado interés en ciertas normas de rigor y por la creencia en la posibilidad de establecer conocimientos musicales positivos y útiles.

El contraste entre la "nueva musicología" y el neoempirismo difícilmente podría ser más fuerte. Aunque la nueva musicología no puede ser (vista) simplemente (como) una rama del postmodernismo, la influencia del pensamiento postmodernista es claramente evidente. De la misma manera, aún cuando el reciente empirismo musical no es un mero apéndice del positivismo², el parecido familiar es innegable. Todavía, la lucha intelectual preeminente de nuestro tiempo es la del positivismo y el postmodernismos, dos aproximaciones académicas ampliamente miradas como enemigas mortales. ¿Cómo han surgido estas metodologías diametralmente opuestas y qué debe aprender un erudito académico de tal contraste? ¿Cómo, sin lugar a duda, debería uno manejar la investigación musical?

\footnotetext{
1 Este crecimiento en las pesquisas académicas empíricas se nota en la inauguración de varias revistas, incluida "Psicomusicología" (1981), “Estudios empíricos en las artes” (1982), “Percepción musical” (1983), “Musicae scientiae” (de la ciencia de la música, 1997) y “Musicología sistemática" (1998)

2 Debería notarse que el término 'positivismo' raramente es usado por los modernos empiristas; sin embargo, es una designación usada comúnmente en humanidades y, de ahí, nuestro uso aquí. Para una discusión de las llamadas "guerras culturales”, ver: Alan Sokal y Jean Bricmont, Fashionable Nonsense: Postmodern Intellectuals' Abuse of Science, New York: Picador, 1998; y Joseph Natoli's A Primer to Postmodernity, Oxford: Blackwell Publishers, 1997, notably Chapter 8: Postmodernity's War with Science.

3 Ver Belsey (1993), Feyerabend (1975), Foucault $(1970,1977)$, Hartsock

(1990), Kuhn (1962/1970), Natoli (1997).
} 
Por metodología, entiendo cualquier abordaje formal o semiformal para adquirir comprensión o conocimiento. Una metodología puede consistir en un conjunto de reglas fijas o normas, o en orientaciones casuales, sugerencias o heurística. Cada cierto tiempo, emerge una metodología particular que se comparte entre varias disciplinas. Un ejemplo es el llamado paradigma de Neyman-Pearson para la investigación empírica inductiva, comúnmente usada en las ciencias físicas (Neyman y Pearson, 1928, 1967). Pero no todas las disciplinas adoptan las mismas metodologías ni deberían hacerlo.

Diferentes metas investigativas, diferentes temores y diversas oportunidades y disposiciones pueden influir en la adopción y desarrollo de metodologías investigativas. Para un proyecto dado, algunos métodos probarán ser más convenientes que otros. Parte de la responsabilidad académica, entonces, es identificar y refinar métodos apropiados al campo de estudio. Tal responsabilidad incluye el reconocimiento de cuándo un método investigativo establecido deja de ser apropiado y (cabe) la adaptación de la investigación de uno para tomar ventaja de nuevos puntos de vista que tengan que ver con la conducción del proceso, cuando tales nuevos enfoques vayan siendo conocidos.

\section{Dos culturas.}

Históricamente, las diferencias metodológicas más pronunciadas pueden ser observadas en el amplio contraste entre las ciencias y las humanidades (por conveniencia, usaré en este artículo el término "humanidades" para referirme tanto a las humanidades como a las artes). En la academia humanística, los métodos investigativos incluyen los historiográficos, los semióticos, los deconstructivos, los feministas, los hermenéuticos y muchos otros. En las ciencias, los principales abordajes incluyen la modelación y la simulación, el análisis por síntesis y los enfoques experimentales y correlativos.

Muchos académicos presumen que las diferencias metodológicas reflejan desacuerdos filosóficos básicos acerca de la investigación. Pienso que tal creencia enmascara las causas verdaderamente fundamentales de divergencia metodológica. Como argüiré en este artículo, las principales diferencias de método entre las disciplinas pueden remontarse hasta los materiales y circunstancias del campo particular de estudio. Vale decir que, típicamente, esas diferencias reflejan divergencias concretas entre campos (o subcampos), más que entre enfoques filosóficos. Ésta es la razón, opino, por la que musulmanes y cristianos, ateos y anarquistas, liberales y libertarios, hallan poca dificultad en trabajar unos con otros en la mayor parte de las disciplinas. Aunque profundas creencias personales puedan motivar a un individuo para trabajar sobre ciertos problemas, las opiniones filosóficas profundas de uno tienen, a menudo, poco que ver con su aproximación académica (a los objetos de estudio).

\section{Filosofía del conocimiento y metodología investigativa.}

En cuanto a los asuntos metodológicos académicos, vale la pena dividir la discusión en dos tópicos correlativos. Uno de ellos tiene relación con amplios asuntos 
epistemológicos, mientras que el otro tiene que ver con los problemas concretos de cómo adelantar el trabajo académico en la práctica. En suma, podríamos distinguir, con utilidad, la filosofía del conocimiento, por una parte, de la metodología investigativa, por otra. Uno espera, con razón, que las posiciones que mantenemos acerca de la filosofía del conocimiento, informarán y moldearán los procedimientos concretos que usamos en nuestro diario quehacer investigativo. Sin embargo, la información fluye en ambas direcciones. Las experiencias investigativas prácticas también proveen importantes lecciones que dan forma a nuestras filosofías del conocimiento.

En el entrenamiento de nuevos investigadores, parecería que las disciplinas académicas difieren a menudo en el peso relativo dado a la filosofía del conocimiento en comparación con la metodología. Mi experiencia con psicólogos, por ejemplo, es que ellos reciben, por lo general, un entrenamiento excelente en los aspectos prácticos de los procesos investigativos. En la conducción de un proyecto, (v. gr.) hay innumerables trampas que deben evitarse, tales como el sesgo confirmativo, las características de demanda y las comprobaciones múltiples. Éstas son las clases de cosas que los psicólogos experimentales aprenden a reconocer y, por tanto, diseñan estrategias para evitarlas o minimizarlas. Pero la mayoría de los psicólogos que he encontrado, recibieron un entrenamiento comparativamente menor en la filosofía del conocimiento; apenas han oído algo de Hume o Popper, van Quine y Lakatos, Gellner, Laudan y otros. Es intrigante el contraste con el entrenamiento de literatos y lingüistas. Apenas habrá algún estudioso inglés, formado en las décadas recientes, que no haya leído un buen número de libros atinentes a la filosofía del conocimiento. La lista de autores difiere, sin embargo, (se notará) el énfasis sobre los escritores anti- fundacionalistas: Kuhn y Feyerabend, Derrida y Foucault, Lacan, Lyotard, etc. Por otra parte, la mayoría de los eruditos ingleses recibe relativamente poca preparación en la metodología investigativa y, frecuentemente, ello se hace evidente por la confusión que experimentan los jóvenes académicos cuando se embarcan en su propia investigación: a menudo no saben cómo empezar o qué hacer.

Las diferencias filosóficas y metodológicas entre las ciencias y las humanidades pueden ser causa de considerable malestar para aquéllos de nosotros que trabajan en la frontera entre ambas. Como musicólogo cognitivo, constantemente debo preguntarme si debería estudiar la mente musical como un investigador de las humanidades o como un científico. Habiendo dado alguna luz a cuestiones metodológicas, mi propósito en este artículo es compartir algunas observaciones sobre estos (y otros) asuntos convulsos pero esenciales.

\section{Panorama.}

Mi meta en este escrito es hacer un recuento de las divergencias metodológicas que surgen entre las disciplinas y tratar de entender sus orígenes y méritos específicos. Por lo que ya he aprendido, pienso que las circunstancias investigativas concretas son especialmente formativas. Pero, antes de entrar en materia, debo referirme a los ruidosos debates, ciertamente interesantes, sobre la filosofía del conocimiento. En particular, es apropiado tornar la atención al debate, a menudo agrio, entre el 
Empirismo y el Postmodernismo.

Desde luego, no todas las ciencias son empíricas y no todas las disciplinas humanísticas son postmodernas (en su enfoque actual). El campo de las matemáticas (que es popularmente considerado "científico" a menudo) depende, casi exclusivamente, de métodos deductivos más que empíricos. Homólogamente, aunque el postmodernismo ha sido un paradigma dominante en muchas disciplinas humanísticas en las dos décadas pasadas, existen otras tradiciones metodológicas en ellas. La razón por la que propongo enfocar las tradiciones empiristas y postmodernistas es que ellas son, aparentemente (al menos) las más irreconciliables. Creo que tenemos mucho qué aprender del examen de tal debate.

Este proyecto se divide en dos partes. En la parte I, destaco algo de la historia intelectual que se halla tras el empirismo contemporáneoy el postmodernismo. La parte II se concentra más específicamente en la metodología. Particularmente, identifico las que pienso ser causas principales que conducen a la adopción de metodologías diferentes en campos y subcampos (asimismo) diferentes. La parte II suministra también ejemplos históricos de disciplinas que han cambiado dramáticamente sus preferencias metodológicas en respuesta a nuevas circunstancias. Mi argumento es que los recursos disponibles para la investigación musical están evolucionando rápidamente y que la musicología tiene mucho qué ganar adaptándose a métodos empíricos en la solución de variados problemas. Concluyo destacando algunas ideas básicas subyacentes a lo que podría llamarse "Neoempirismo".

\section{PARTE I: FILOSOFÍA DEL CONOCIMIENTO}

\section{Empirismo y ciencia.}

La definición del diccionario para "empírico" es sorprendentemente inocua para aquéllos de nosotros que estudiamos las artes, a quienes se enseñó a usarla como un término de burla. Conocimiento empírico significa, simplemente, el adquirido por medio de la observación. La ciencia es un ejemplo de acercamiento empírico al conocimiento. De hecho, muchas de las cosas que hacen los musicólogos históricos tradicionales, son empíricas: descifrar manuscritos, estudiar partituras y oír ejecuciones musicales.

La complejidad filosófica comienza cuando uno se pregunta cómo aprendemos mediante observación. La respuesta clásica es que lo hacemos por un proceso denominado inducción. La inducción implica hacer un conjunto de observaciones específicas y formular luego un principio general a partir de estas observaciones. Por ejemplo, de haber golpeado mi dedo gordo del pié en tantas ocasiones de mi vida, me he formado un convencimiento general de que el rápido movimiento de ese dedo contra objetos pesados está destinado a evocar dolor. Podría decirse que he aprendido de la experiencia (aunque mis continuos choques de la misma laya me hacen preguntarme qué bien he aprendido esa lección).

El filósofo escocés del siglo XVIII, David Hume, reconoció que hay serias dificultades con el concepto de inducción. Hume notó que ninguna cantidad de observación podría 
jamás resolver la verdad de una afirmación cualquiera. Por ejemplo, sin importar cuántos cisnes blancos uno vea, el observador jamás estaría autorizado para concluir que todos los cisnes son blancos. Usando lenguaje postmodernista, diríamos que uno no puede, legítimamente, elevar observaciones locales al status de verdades globales.

Varios intentos serios han hecho los filósofos para resolver el problema de la inducción. Tres de tales intentos han sido influyentes entre los círculos científicos: la falsación o falsacionismo (falsificationism), el convencionalismo y el instrumentalismo. Pero estos intentos sufren de serios problemas propios. En esas tres filosofías, la validez del conocimiento empírico se preserva mediante la pérdida de cualquier reclamo fuerte de verdad absoluta.

Una de las epistemologías más influyentes en el Empirismo del siglo XX fue la filosofía del convencionalismo. La afirmación clásica se encuentra en "El objetivo y la estructura de la teoría física” de Pierre Duhem, publicada originalmente en 1905 y reimpresa innumerables veces durante la (pasada, para esta traducción) centuria. En su libro, Duhem nota que la ciencia nunca proporciona teorías o explicaciones de alguna última realidad. Las entidades teóricas y las leyes matemáticas son meras convenciones que sintetizan ciertos tipos de relaciones. Nunca podrá determinarse si las teorías científicas son "verdaderas" en el sentido de explicar o capturar una realidad subyacente. Tales teorías son meras convenciones que ayudan a los científicos a organizar los patrones observables del mundo.

Una variación del convencionalismo, conocida como instrumentalismo, afirma semejantemente que el empirismo no provee explicaciones últimas: el ingeniero no tiene un entendimiento profundo de por qué un puente no se cae. Más bien, el ingeniero se apoya en teorías (que se toman como) herramientas que son razonablemente predictivas de resultados prácticos. Para el instrumentalista, las teorías no se juzgan por su "verdad" sino, más bien, por su utilidad predictiva.

El intento mejor conocido de resolver el problema de la inducción fue formulado por Karl Popper en 1934. Popper aceptó que ninguna cantidad de observación podría alguna vez verificar que una proposición dada es cierta. Es decir, un observador no puede comprobar que todos los cisnes son blancos. Sin embargo, Popper argüía que uno puede estar seguro de la falsedad. Por ejemplo, la observación de un único cisne negro permitiría al observador concluir que la afirmación de que todos los cisnes son blancos es falsa. De igual manera, Popper se esforzó por explicar el crecimiento del conocimiento como producto de podar el árbol de las posibles hipótesis, usando la podadora de la falsación. Verdad es lo que queda después de que las falsedades han sido cortadas.

El punto de vista de Popper fue criticado por van Quine, Lakatos, Agassi, Feyerabend y otros. Uno de los problemas es el de que no está suficientemente claro qué es falsificado por una observación falsante. Puede ser que la observación misma sea incorrecta, que el fenómeno estudiado no esté definido en buena forma o (que) la estructura teórica general dentro de la cual se inscribe la hipótesis (no es la adecuada). Por ejemplo, el observador de un supuesto cisne negro podría haber estado borracho, o el cisne pudiera haber sido pintado o el animal podría haber sido de diferente especie. Otro problema con relación a esto sería más bien técnico y difícil 
de describir suscintamente. Con el fin de evitar un rechazo prematuro de su teoría, Popper abandonó la noción de observación falsante y la reemplazó por el concepto de fenómeno falsante. Pero aún para establecer que un fenómeno es falsante, los investigadores deben embarcarse en una actividad de verificación (una actividad que el mismo Popper sostenía como imposible). En la metodología de Popper, el fastidioso problema de la verdad inductiva vuelve a entrar por la puerta trasera.

A pesar de tales dificultades, el falsacionismo (aceptación de la falsación) de Popper ha permanecido altamente influyente en la práctica diaria de la investigación empírica. En las revistas profesionales de ciencia, los editores dan de baja a afirmaciones de que tal y tal cosa es verdad o de que tal teoría ${ }^{4}$ está verificada o, incluso, de que los datos apoyan tal o cual hipótesis. Por el contrario, el lenguaje estereotípico para los reclamos científicos es: la hipótesis nula fué rechazada, o bien, los datos son consistentes con tal o tal hipótesis. Desde luego, este circunspecto lenguaje se abandona en los escritos secundarios o en los de divulgación científica popular, como también en conversaciones informales de los hombres de ciencia. Esta brecha entre el escepticismo oficial y la certeza coloquial sería un asunto apropiado para el estudio de los sociólogos de la ciencia.

Otra epistemología científica, menos influyente, del siglo XX fue el positivismo, que nunca hizo una propuesta para resolver el problema de la inducción. Sin embargo, merece una breve mención aquí por dos razones. Primera: el positivismo lógico atrajo la atención al asunto del lenguaje y del significado en el discurso científico; segunda: el positivismo ha sido blanco preferido de las críticas postmodernistas.

El positivismo comenzó como filosofía social en Francia, iniciado por Saint Simon y Comte e influyó sobre las ciencias en la primera parte del siglo XX. Sus asertos fueron articulados por el llamado Círculo de Viena (que incluía a Schlick y Carnap) y culminaron en la doctrina clásica de A. J. Ayer en 1936. En ciencia, el positivismo lógico mantuvo su vigencia apenas entre 1930 y 1965, aproximadamente. No obstante, tal influencia se restringió casi exclusivamente a la psicología estadounidense; sólo una pequeña minoría de empiristas se consideró alguna vez positivista.

Por casi todo el siglo XX, la posición preeminente de los científicos practicantes (al menos en cuanto a aquéllos que han tenido el cuidado de comentar sobre tales materias) ha sido el convencionalismo o el instrumentalismo. El énfasis popperiano sobre las hipótesis falsantes (consistente tanto con el convencionalismo como con el instrumentalismo) se ha demostrado altamente influyente en la práctica diaria debido, en gran medida, al método de falsación inductiva de base estadística de Pearson, Neyman y Popper. Muchos epistemólogos consideran que los escritos más importantes e influyentes de Popper son sus apéndices sobre Probabilidad y estadística.

De ninguna manera es ésta una historia completa de la filosofía de la ciencia en el siglo XX pero, antes de continuar nuestro recuento, es apropiado que volvamos nuestra atención al postmodernismo.

4. En este artículo, la palabra 'teoría' deberá ser interpretado ampliamente para significar cualquier reclamo (conclusión, afirmación), hipótesis, teoría, interpretación o punto de vista.

5. Nota del traductor: la hipótesis nula es una expresión que se entendería mejor como hipótesis contraria ya que, lingüística y lógicamente hablando, nulo es algo que no vale o que no existe y la idea quedaría mejor significada por el adjetivo que hemos sugerido o, quizás, por anuladora. 


\section{Postmodernismo.}

El postmodernismo es muchas cosas y cualquier intento de sintetizarlo corre el peligro de la sobresimplificación (sin duda, una de las afirmaciones principales del postmodernismo es la de que uno no debe tratar de representar la visión de otros sobre el mundo). De la misma manera como los filósofos de la ciencia están en desacuerdo unos con otros, aquéllos que se autodenominan postmodernistas no piensan unánimemente. Pero hay un número de temas comunes que tienden a ser recurrentes en los escritos postmodernistas. Se trata de un movimiento filosófico que se centra en cómo los significados se construyen y cómo el poder es usurpado y ejercido por medio del lenguaje, la representación y el discurso ${ }^{6}$.

El postmodernismo está interesado en la academia porque las labores académicas se cuentan entre las actividades más importantes de nuestra sociedad, entre aquéllas que confieren sentido. Los postmodernistas están especialmente interesados en la ciencia, principalmente porque, al menos en las sociedades occidentales, la ciencia mantiene un poder de persuasión mayor que cualquier otra institución. Se trata de un poder del que los más poderosos políticos sólo pueden expresar envidia.

El postmodernismo comienza desde una posición sorprendentemente similar a la antiverificacionista de Popper y a la convencionalista de Duhem. Donde éste y Popper predicaban que la verdad es inconocible, los postmodernistas asumen que no hay una verdad absoluta por conocer. Más precisamente, la verdad debería ser entendida como una construcción social que se relaciona con una perspectiva local o parcial sobre el mundo. Nuestro error es asumir que, como observadores, podemos saltar afuera de la caja que es nuestro mundo. No hay, entonces, tal perspectiva objetiva.

Hay, más bien, un vasto número de interpretaciones sobre el mundo. En esto, el mundo es afín a una serie de textos. Tal como seilustra en los escritos de Jacques Derrida, cualquier texto puede ser deconstruido para que revele múltiples interpretaciones, ninguna de las cuales puede reconstruirse como completa, definitiva o privilegiada. De esto, los postmodernistas concluyen que no hay verdad objetiva y, de igual modo, que no hay base racional para el juicio moral, estético o epistemológico.

Si no hay base absoluta para estos juicios, ¿cómo hace la gente para tomar las decisiones que toma? Los logros más exitosos del postmodernismo se han dado en el llamado de atención a las relaciones de poder que existen en cualquier situación en la que un individuo hace alguna afirmación. Como Nancy Hartsock ha sugerido, "la voluntad de poder es inherente al esfuerzo de crear teoría". Como el político o el negociante, los académicos están, consciente o inconscientemente, motivados por el deseo de apoderarse de recursos y establecer influencia. En manera diferente a los políticos o los negociantes, nosotros los académicos predicamos no tener una agenda oculta, en un autoengaño que nos convierte en los más peligrosos entre todos los cuenteros.

6. En las fuertes palabras de Foucault: "No hay establecimiento de relación de poder sin la correlativa constitución de un campo del conocimiento, ni un conocimiento que no presuponga y establezca, al mismo tiempo, relaciones de poder" (pág. 27) 
Los miembros más poderosos de la sociedad son quienes son capaces de establecer y proyectar sus propios cuentos en la manera de las llamadas "narrativas magistrales". Estas narrativas se relacionan, no sólo con reclamos de verdad, pero también con fines morales y artísticos. Los "cánones" del arte y del conocimiento son los de las obras exaltadas por, y puestas al servicio de, las élites sociales. Ya que las obras artísticas dan legitimidad a quienes las producen: "una obra de arte es un acto de poder" (Rahn, 1993).

Este punto de vista acerca del mundo, claramente pesimista, podría llevarlo a uno a la desesperación. Si no hay un poder legítimo, ¿cómo actúa una persona consciente para (ayudar a) construir un mundo mejor? El postmodernismo ofrece varias estrategias que podrían mirarse como servidoras del objetivo expuesto. A saber, el postmodernista sirve a la causa por medio de una suerte de periodismo investigativo que expone cómo las conductas son egoístas. A lo sumo, el postmodernismo es un cucharón democratizante que agita la sopa política y resiste el asedio de un poder único. Al crear una especie de caos de significado, cuestiona los cánones existentes, subvierte las narrativas magistrales y da nacimiento a lo que ha sido llamado "la política de la diferencia".

\section{FEYERABEND Y EL DEBATE ENTRE GALILEO Y LOS ESCOLÁSTICOS.}

En el mundo de las ciencias, una demostración de tales relaciones de poder se examina en la obra de Feyerabend. En su libro Contra el método, el autor utilizó él mismo el método científico para mostrar los errores del discurso de la ciencia y el papel del poder en un debate presuntamente racional.

Vale la pena discutir con algún detenimiento el trabajo de Feyerabend porque ha producido malentendidos de amplia difusión, algunos de ellos promovidos por Feyerabend mismo.

El mundo científico contemporáneo acata ciertos estándares de evidencia en los debates, Por ejemplo, cuando hay dos teorías conflingentes, los científicos tratan de construir un "experimento crítico" en el que ambas teorías son sometidas a prueba y, de ello, resulta que una de las teorías sea rechazada. Además, los métodos científicos contemporáneos fruncen el ceño ante las llamadas "hipótesis ad hoc". Supongamos que los resultados de un experimento crítico van en contra de mi teoría favorita. Yo podría tratar de salvarla arguyendo que el experimento fallaba en varios aspectos. Podría decir que la razón de que fallara en ser consistente con mi teoría se debe a que el planeta Mercurio estaba en retrogradación el día en que el experimento se llevó a cabo o que mi teoría es cierta siempre, excepto el tercer miércoles de cada mes. Desde luego, las hipótesis ad hoc no necesitan ser tan graciosas. Otras más creíbles podrían argumentar que el observador estaba pobremente entrenado, que el equipo no estaba apropiadamente calibrado, que el grupo de control estaba incorrectamente integrado, etc. Aunque una hipótesis ad hoc podría ser cierta, tales apelaciones son consideradas un mal protocolo cuando el motivo, patentemente, es descartar la falla de una formulación teórica.

Feyerabend utiliza el estudio de caso del famoso debate entre Galileo y los 
escolásticos. En la percepción popular de esta historia, Galileo argüía que el sol estaba situado en el centro del sistema solar y los escolásticos, guiados por el dogma religioso, mantenían que la tierra estaba en el centro del universo.

Históricamente, este punto de vista no es del todo correcto, como señala Feyerabend. Los escolásticos argumentaban que el movimiento es relativo y que no hay, en principio, manera de determinar si la tierra giraba alrededor del sol o si era el sol el que rotaba alrededor de la tierra. Ya que la sola observación no podía resolver la cuestión, los escolásticos alegaban que la Biblia implica que la tierra mantiene una posición central.

Galileo y los escolásticos, entonces, se pusieron de acuerdo en un posible experimento crítico. Supónga que su cabeza representa la tierra. Si usted rota su cabeza en una posición fija, los ángulos entre varios objetos del recinto permanecerán fijos; pero, si usted camina en un círculo alrededor del salón, los ángulos visuales entre varios objetos cambiarán. Cuando se acerque usted a dos objetos, el ángulo que los separa aumentará e, inversamente, cuando se aleje usted, ese ángulo decrecerá.

De acuerdo con esa lógica, si la tierra estaba en movimiento, entonces uno debería ser capaz de observar leves cambios angulares entre las estrellas a lo largo del año. Usando su invención de nuevo cuño, el telescopio, Galileo hizo, indudablemente, cuidadosas mediciones de las relaciones angulares entre las estrellas durante el curso de un año, pero no encontró cambios. En realidad, él realizó un experimento crucial, cuyos resultados no eran consistentes con la idea de que la tierra estaba en movimiento. ¿Cómo respondió él a este resultado? sugirió que la razón por la que los cambios de paralaje no podían ser observados era el que las estrellas estuviesen extremadamente lejanas.

Feyerabend señaló que ésta es una hipótesis ad hoc. Un experimento crítico fue realizado para determinar si la tierra o el sol estaban en movimiento y la teoría de Galileo perdió la partida; pero éste tuvo la audacia de defender su teoría ofreciendo una hipótesis ad hoc. Por los estándares científicos modernos, uno habría tenido que concluir que la teoría de los escolásticos era superior y que, como científico, Galileo mismo debería haber reconocido que la evidencia era más consistente con la teoría geocéntrica.

Obviamente, desde nuestra moderna perspectiva, Galileo hizo bien en perseverar en su teoría heliocéntrica del sistema solar pues, como se sabe, su hipótesis ad hoc que consideraba la extrema distancia de las estrellas es considerada correcta por los astrónomos de hoy.

De esta historia, Feyerabend saca las siguientes conclusiones: Primero, el progreso de la ciencia puede depender de malos argumentos y de datos ignorados; segundo, Galileo debería ser reconocido, nó como un gran científico, sino como un exitoso propagandista; tercero, si Galileo hubiera obedecido los estándares modernos del método científico, el resultado habría sido científicamente erróneo; cuarto, la norma contra las hipótesis ad hoc en la ciencia, puede producir resultados científicamente incorrectos; quinto, el uso de experimentos cruciales también puede producir resultados incorrectos científicamente; sexto, no hay regla metodológica que pueda asegurar un resultado correcto; séptimo, no hay un método científico; octavo, en 
asuntos de metodología, concluye Feyerabend, "todo vale". Como Popper y Lakatos, Feyerabend argüía que no existe un conjunto de reglas que puedan garantizar el progreso del conocimiento.

Para juzgar sobre el trabajo de este último, necesitamos volver nuestra atención, tanto a los éxitos, como a los fracasos. Empecemos por señalar algunos problemas. Recordemos que el problema de la inducción es el de cómo pueden extraerse conclusiones generales de un conjunto finito de observaciones. Consideremos las conclusiones cuarta y quinta. Él anota que dos reglas del método científico (a saber, la que prohíbe las hipótesis ad hoc y la instrucción de diseñar experimentos cruciales) fallaron en producir un resultado válido en el caso de Galileo. A partir de estas dos observaciones históricas, Feyerabend formula la conclusión general: ninguna regla metodológica asegurará un resultado correcto. Ya habrá reconocido el lector que éste es un argumento inductivo, como decía Hume, y jamás podremos estar seguros de que generalizar a partir de observaciones específicas produzca una generalización válida.

El demostrar que unas reglas metodológicas no funcionan en un caso particular, no nos permite reclamar que todas las reglas metodológicas son erróneas. Aún si uno pudiera demostrar que todas las reglas metodológicas son inadecuadas, no podría lógicamente concluir que no existen reglas metodológicas verdaderas pertinentes.

Otro problema con la argumentación de Feyerabend es que exagera la importancia de Galileo en la promoción de la teoría heliocéntrica. Las creencias y los argumentos de una sola persona son típicamente limitados. El conocimiento está distribuido socialmente y las ideas calan sólo cuando una porción amplia de la población está preparada para ser convencida. De hecho, los argumentos galileanos no produjeron la adopción inmediata de la teoría heliocéntrica del sistema solar. La teoría no ganó muchos adeptos sino hasta cuando Kepler demostró que los planetas se mueven en órbitas elípticas; las leyes de Kepler convirtieron la teoría heliocéntrica en un sistema mucho más simple para describir las órbitas planetarias. En suma, la fama de Galileo y su importancia como campeón científico es primariamente retrospectiva y ahistórica.

El trabajo histórico y analítico de Feyerabend es insuficiente para sostener su conclusión general, a saber, que la única regla correcta en metodología es "todo vale". Más aún, su opinión no se sostiene bajo la observación. Cualquiera que observe una reunión de un grupo académico entenderá que, en sus debates, nunca es cierto que "todo vale". Todas las disciplinas tienen estándares más o menos estrictos de evidencia, de argumentación sólida y demás (criterios). Aunque algunos académicos (quizás) pudieran desear que los debates se dirimieran por medio de un combate físico, para la mayoría de los científicos, tales "métodos" no son ya admisibles. Podría ser que ninguna receta metodológica garantice el avance del conocimiento, pero, aun así, no es el caso de "todo vale".

Por el lado positivo, Feyerabend atrajo la atención al entorno social y político en que la ciencia tiene lugar. Estableció que su principal motivo para escribir "Contra el Método" había sido "humanitario, no intelectual". Quería proveer soporte retórico para los marginados y desposeídos. Al convocar la atención sobre la sociología de la ciencia, Feyerabend y sus seguidores encontraron una fuerte resistencia de los científicos mismos. Hasta hace poco, la mayoría de ellos rechazaron la opinión de que 
la ciencia está moldeada por un contexto sociopolítico. A pesar de las fallas científicas, eso no significa (necesariamente) que los académicos que trabajan con la sociología de la ciencia hayan estado haciendo un buen trabajo.

\section{KUHN Y LA INVESTIGACIÓN PARADIGMÁTICA.}

El más influyente estudio de la ciencia sea probablemente "La estructura de las revoluciones científicas" de Thomas Kuhn. Como historiador de las ciencias, Kuhn se distinguió por describir cómo nuevas ideas ganaban aceptación en una comunidad científica.

A partir de sus estudios sobre la historia de la ciencia, Kuhn distinguía dos tipos de ella: la normal y la revolucionaria. La normal es una suerte de actividad de rompecabezas en la que la teoría científica prevalente es aplicada en varias tareas y las pequeñas anomalías con respecto a ella son investigadas y resueltas dentro de la práctica de esa ciencia "normal". Sin embargo, con el paso del tiempo, algunas anomalías fallan en ser resueltas y una minoría de científicos empieza a creer que la teoría prevalente (o paradigma) está equivocada en su fundamento.

La ciencia revolucionaria rompe con el paradigma establecido y propone una interpretación alternativa, que encuentra una cerrada resistencia. Aunque la nueva teoría podría explicar las anomalías en la anterior, inevitablemente habrá cosas que aún no pueden ser explicadas por ella. Los opositores del nuevo paradigma contrastan estas fallas con los conocidos éxitos del anterior (en parte, los problemas con el nuevo paradigma pueden atribuirse al hecho de que la nueva teoría aún no se ha beneficiado con años de ciencia normal que resuelvan los problemas aparentes que pueden ser explicados usando la antigua).

Un reclamo importante de Kuhn es que los debates entre los seguidores de una y otra teorías no son racionales. El cambio de paradigma es afín a una conversión religiosa: o bien se ve el mundo de acuerdo con uno de ellos o bien, con el otro; los seguidores de las dos teorías en conflicto son incapaces de una discusión mutua razonada y hablan uno por encima del otro. Términos técnicos como "electrón" empiezan a tener significados diferentes para los dos bandos.

Kuhn alegaba que no hay posiciones neutras u objetivas desde las cuales pueda uno juzgar los méritos relativos de ambos lados. Consiguientemente, caracterizó esos paradigmas como "inconmensurables", es decir, no medibles mediante el uso de un solo patrón. Los cambios de teoría ocurren, decía, nó porque los defensores del viejo paradigma lleguen a convencerse por (los méritos intrínsecos de) el nuevo. En vez de eso, arguye Kuhn, nuevos paradigmas reemplazan los viejos porque los científicos que sostenían éstos mueren y los defensores del nuevo pueden situar a sus colegas y estudiantes en posiciones de poder importantes (profesores, editores de revistas, agencias de becas y recursos para la investigación). Una vez que los abogados del nuevo paradigma se toman el poder, los textos de la disciplina son reescritos, en forma tal que el cambio revolucionario es presentado como un paso natural e inevitable en el progreso constante y continuo de esa disciplina.

Aunque el trabajo de Kuhn conmovió las ciencias sociales, comparativamente 
dejó poca huella en las ciencias exactas y naturales. "La estructura de las revoluciones científicas" presentaba las ciencias como afines a la moda: los cambios no surgen de algún tipo de debate racional; el cambio está determinado, simplemente, por quien (o quienes) detenta el poder. Aunque Thomas Kuhn negaba haber argüído que la ciencia no progresa, su estudio de la historia de la ciencia implicaba que el "progreso científico" es una ilusión perpetrada por científicos que reconstruyen la historia para situarse ellos mismos (y su paradigma) en el pináculo de una larga cadena de logros.

Muchos académicos de las ciencias sociales y las humanidades aplaudieron a Kuhn porque su imaginería removió la ciencia de su alto sitial epistemológico: la presunta autoridad de la ciencia no podía ser garantizada. Como en el caso de las diferentes culturas alrededor del mundo, no hay una unidad de medida por la que alguien pueda afirmar que una cultura científica es mejor que otra.

Los escritos de Kuhn también hallaron simpatías entre aquellos científicos (y otros académicos) cuyos puntos de vista, rutinariamente ignorados por sus colegas, los ponían fuera de la corriente principal; para ellos, el mensaje kuhniano era altamente estimulante: la razón por la que la otra gente no "nos" entiende ni les importa lo que "decimos", es que ellos están inmersos en el viejo paradigma y ninguna cantidad de debate razonado convencerá a los poderes existentes. En suma, la caracterización de Kuhn para la ciencia confiere una medida de comodidad a los marginados y desposeídos.

Poco después de la publicación del libro de Kuhn, un joven filósofo bengalí llamado Jaqdish Hattiangadi, escribió una detallada crítica de la obra. Aunque Kuhn se presentaba a sí mismo como historiador de la ciencia con grandes simpatías por ella, Hattiangadi declaró que esa obra removía cualquier posibilidad de que la ciencia pudiera ser vista como una empresa racional. Aunque Kuhn jamás dijo tanto como eso, su teoría tuvo repercusiones significativas: por ejemplo, un químico que cree que la química moderna es mejor que la antigua, simplemente debería desengañarse. Hattiangadi reclamó que, o bien no hay progreso en la ciencia, definitivamente, o la imagen que da Kuhn de ella está equivocada. Y concluyó, además, que fallaba en dar cuenta de la difundida convicción general de que el progreso científico es un hecho. Más aún, Hattiangadi predijo, ya desde 1963, que el libro de Kuhn se volvería salvajemente exitoso entre los académicos sociales y humanistas, una predicción que se comprobó correcta (después).

\section{POSTMODERNISMO: UNA VALORACIÓN}

Con ese telón de fondo en su lugar, volvámos a nuestra discusión del postmodernismo. En general, el postmodernismo traba lucha con el proyecto de la Ilustración de derivar verdades absolutas o universales del conocimiento particular. Esto significa que el postmodernismo postula una radical oposición a la inducción: no podemos generalizar de lo particular; lo global no se sigue de lo local.

A primera vista, pareciera que el postmodernismo sería tan crítico de Feyerabend y Kuhn como de los positivistas, ya que los argumentos de ambos descansan sobre la presunción de que podemos aprender lecciones generales a partir de ejemplos 
históricos específicos. Sin embargo, al postmodernismo importan menos esos asuntos convulsivos que la meta de inflingir daños entre aquéllos que reclaman conocimiento fuerte. Concordantemente (con esto), las obras de Feyerabend y Kuhn se miran como aliadas en la tarea de destronar la presunta autoridad de la ciencia (exacta y natural).

Claro que el postmodernismo también tiene sus críticos. Mucho del reciente descontento con esa filosofía (proviene de que) parece negar la posibilidad de un cambio humano significativo. Por ejemplo, muchas pensadoras feministas han rechazado la visión postmodernista porque ésta niega (la posibilidad de) una alta base moral. En su cabildeo por un cambio político, la mayoría de las feministas se han motivado por un sentido de injusticia. Pero si no hay preceptos absolutos de justicia, entonces el mensaje que da el postmodernismo a las feministas es que ellas están simplemente comprometidas en maniobras maquiavélicas en luchas por (mayor) poder. En palabras de Joseph Natoli, "la política postmodernista nada tiene que ver con lo substancial sino sólo con lo táctico" (1997, p. 101); por una parte, incita a las feministas a quitar poder al establecimiento masculino, pero, al tiempo, les dice que no crean, del todo, que sus acciones están justificadas. Comprensiblemente, muchas feministas están incómodas con esta contradicción.

El meollo del problema, pienso, es evidente en las dos proposiciones siguientes, asociadas con el postmodernismo:

(1) No hay interpretación privilegiada

(2) Todas las interpretaciones son igualmente válidas.

Tal como la escritora postmodernista Catherine Belsey ha notado, el postmodernismo ha sido mal recibido por el público, primordialmente porque ha fallado en distinguir entre el sentido y el sinsentido. Esa es la conclusión lógica para aquéllos que creen que (2) es, simplemente, una réplica de (1).

Si aceptamos que no hay interpretación privilegiada y de ello no se sigue necesariamente el que todas las interpretaciones sean igualmente válidas [es decir, si aceptamos (1) pero nó (2)], debe concluirse que algunas interpretaciones deben ser "mejores" que otras y viene luego la pregunta de que se significaría por "mejor".

Los postmodernistas han hecho un buen papel en incitar a los académicos a pensar cuidadosa, lateral y autorreflexivamente. Pero, contrariamente, también han promovido una investigación descuidada y un desinterés en la prosecución del rigor; han llamado la atención sobre el contexto social y político del conocimiento y de sus reclamos, pero se aventuran muy lejos cuando concluyen que la realidad se construye socialmente más bien que estar socialmente mediatizada; juega un importante papel cuando nos mueve a pensar en las relaciones de poder y, en particular, en cómo ciertos grupos son aislados políticamente porque tienen muy poco control sobre cómo son establecidos los significados. Pero, al mismo tiempo, el postmodernismo subvierte todos los valores y transforma la justicia en meras maniobras tácticas para ganar el poder. Al reducir a éste todas las relaciones, no deja lugar para otras motivaciones humanas. La academia puede tener dimensiones políticas, pero eso no significa que todos los académicos estén fraguando tomas de poder. El postmodernismo 
es importante por cuanto reclama atención al medio simbólico y cultural de la existencia humana, pero, así como debemos reconocer que los seres humanos son entidades culturales, también debemos reconocerlos como entidades biológicas con conocimientos y disposiciones instintivas a priori acerca del mundo, originados en un proceso inductivo de adaptación evolutiva (Plotkin, 1994). Desafortunadamente, Foucault niega cualquier status a los humanos como entidades biológicas cuyo almacenamiento mental (hardware innato) existe para el real propósito de ganar conocimiento acerca del mundo.

Cuando son urgidos ante el problema del relativismo, los postmodernistas soslayan momentáneamente su filosofía y aceptan la necesidad de alguna noción de lógica y rigor. Belsey, por ejemplo, proclama que, como postmodernos, "no deberíamos abandonar la noción del rigor, el proyecto de substanciar nuestras lecturas" (Belsey, 1993, p. 561). De manera semejante, Natoli reconoce que la "Lógica" (1997, p. 162) y la "precisión" (p. 120) ayudan a (armar) narrativas convincentes. No obstante, los postmodernistas, extrañamente, no están interesados en cómo obtener su poder retórico. ¿Qué es "Lógica”? ¿Qué es "rigor"? ¿Qué tiene que ver (el postmodernismo) con esa racionalidad que hace que algunas narrativas sean mentalmente tan seductoras o convincentes? Es exactamente ese propósito el que ha preocupado a los filósofos del conocimiento por los últimos 2,500 años; fue el foco de los esfuerzos de la Ilustración en lo epistemológico, cuando trataba de caracterizar el valor de varias formas de conocimiento en un proyecto que no es o no ha podido ser subvertido por el postmodernismo. Se retoma (debe hacerse) simplemente y de nuevo, la cuestión de qué significa hacer buena academia.

\section{PARTE DOS: FILOSOFÍA DE LA METODOLOGÍA}

Entonces, ¿cómo deberían los académicos adelantar la investigación? ¿Qué nos dice la filosofía del conocimiento acerca de los aspectos prácticos académicos? Como hemos visto, ella sugiere que abandonemos el punto de vista según el cual la metodología es una receta infalible o algoritmo para establecer la verdad. El papel epistemológico de la metodología es mucho más modesto. Al mismo tiempo, lo que el neoempirismo comparte con el postmodernismo es el convencimiento de que la academia ocurre en un reino moral y, por tanto, debería guiarse por consideraciones morales.

\section{Diferencias metodológicas.}

Tal como se dijo en la introducción, una de las principales metas de este proyecto es dar mejor cuenta de por qué las metodologías difieren para las diversas disciplinas. Para perseguir tal fin, delinearemos una taxonomía de las metodologías investigativas, basada en cuatro distintos respectos. En breve, son éstos: 


\begin{tabular}{|c|c|}
\hline $\begin{array}{l}\text { 1. Escepticismo falso-positivo } \\
\text { versus escepticismo falso- } \\
\text { negativo. El primero, sostiene que } \\
\text { las teorías o hipótesis deberían } \\
\text { ser rechazadas si hay la más leve } \\
\text { evidencia en contra; el segundo, } \\
\text { que deben conservarse a no ser } \\
\text { que haya una fuerte evidencia } \\
\text { contraria. }\end{array}$ & $\begin{array}{l}\text { 2. Datos retrospectivos versus } \\
\text { datos prospectivos. Algunas } \\
\text { áreas investigativas (tales como } \\
\text { las que implican el estudio de } \\
\text { manuscritos) tienen únicamente } \\
\text { datos preexistentes; otras (como } \\
\text { los estudios del comportamiento) } \\
\text { tienen oportunidades de recoger } \\
\text { evidencia nuevamente generada. } \\
\text { Los datos prospectivos permiten al } \\
\text { investigador pruebas más rigurosas } \\
\text { de las hipótesis porque puede tratar } \\
\text { de prever las propiedades de los } \\
\text { datos que aún no se han recogido. }\end{array}$ \\
\hline $\begin{array}{l}\text { 3. Teorías de alto riesgo versus } \\
\text { teorías de bajo riesgo. Teorías, } \\
\text { hipótesis, interpretaciones } \\
\text { e intuiciones conllevan } \\
\text { repercusiones morales y } \\
\text { estéticas. Tras la comprobación } \\
\text { de algún nuevo conocimiento, la } \\
\text { carga de evidencia puede cambiar } \\
\text { según sean las consecuencias } \\
\text { de la teoría. Muchas teorías } \\
\text { implican, sin embargo, riesgos } \\
\text { despreciables. }\end{array}$ & $\begin{array}{l}\text { 4. Campos ricos versus campos pobres } \\
\text { en datos. Los campos de estudio } \\
\text { pueden distinguirse también por el } \\
\text { volumen de evidencia pertinente. } \\
\text { Cuando ésta es mínima, los } \\
\text { investigadores de un campo rico } \\
\text { en datos pueden darse el lujo de } \\
\text { suspender el juicio hasta que se } \\
\text { recojan más datos. En contraste, } \\
\text { aquéllos que trabajan en campos } \\
\text { pobres en datos, a menudo deben } \\
\text { interpretar un conjunto de ellos } \\
\text { pequeño y definitivo sin esperanza } \\
\text { de evidencia futura adicional. }\end{array}$ \\
\hline
\end{tabular}

Más abajo, describiré más completamente estas cuatro distinciones (especies). Mi opinión es que los campos de estudio pueden ser útilmente distinguidos por estas cuatro categorías taxonómicas, cada una de las cuales repercute en la formulación de las metodologías apropiadas para cada campo. Puede sugerirse que estas categorías, no sólo nos ayudan a entender mejor por qué divergen las metodologías para los varios campos, sino que nos ayudan a reconocer mejor cuándo una metodología es inapropiada para un determinado campo de estudio.

Por otra parte, puede afirmarse que un cierto campo de investigación experimenta, a veces, grandes cambios en sus condiciones básicas de trabajo; cambios que precipitan nuevas orientaciones metodológicas. Un cierto campo que antes no planteaba motivos 
de preocupación encuentra que, súbitamente, sus últimas teorías comportan alto riesgo moral; otra área de estudio que solía ser pobre en datos puede llegar a estar inundada de nuevas fuentes informativas; una disciplina que antes era retrospectiva puede, inesperadamente, encontrar una clase de eventos para los cuales podría hacer predicciones comprobables. Más adelante en este artículo, discutiré brevemente dos ejemplos de caso acerca de cambios en recursos y en métodos. Mi primer ejemplo es la transformación de la física subatómica en forma tal que sus métodos se van pareciendo, cada vez más, a los de la filosofía y la teoría literaria; el segundo se referirá a la creciente influencia de los métodos empíricos en lo académico musical.

\section{Dos formas de escepticismo.}

Desde el tiempo de los antiguos griegos, por lo menos, la esencia de la academia ha estado cerradamente asociada con el escepticismo, con el que los académicos evidencian mantener relaciones de amor y de odio. Por una parte, todos hemos experimentado perplejidad ante la credulidad de los que aceptan acríticamente lo que pensaríamos que debería evocar oposición o negación. Por otra, hemos experimentado exasperación cuando alguien presenta una beligerante resistencia a lo aparentemente obvio. Lo que una persona mira como reserva prudente, otro podría considerarlo un sinsentido visceral.

La ciencia se pinta a veces como una forma institucional de escepticismo. Desgraciadamente, esta imagen puede dejar la falsa impresión de que las artes y las humanidades no lo son y que, de algún modo, son crédulas, doctrinarias o engañables. Al contrario, la mayoría de las disciplinas humanísticas cultiva también formas institucionalizadas de escepticismo; sin embargo, ese escepticismo es, a veces, diametralmente opuesto al más común entre las ciencias (exactas y naturales).

Estas diferencias están ilustradas en la tabla 1 (arriba). La tabla identifica cuatro estados epistemológicos en relación con cualquier juicio, incluido el de que algo es inconocible. Siempre que se hace una afirmación, aserción o simple insinuación, dos tipos de errores son posibles:

I. Un error "falso-positivo" ocurre cuando decimos que algo es verdadero, útil o conocible, cuando es, en realidad, falso, inútil o inconocible.

II. Un error falso-negativo ocurre cuando reclamamos que algo es falso, inútil o inconocible cuando es, de hecho, verdadero, útil o conocible.

Los metodólogos se refieren a estos errores como del tipo I o del tipo II respectivamente?

7. Un libro de texto estándar sobre métodos científicos dice lo siguiente: "en contraste con las consecuencias de publicar falsos resultados, las consecuencias de un error del tipo II no se ven como muy serias” (Cozby, 1989; p. 147). 
El escéptico falso-positivo tiende a hacer afirmaciones como las siguientes:

"Usted no sabe eso con seguridad".

"Realmente, dudo de que eso sea útil".

"No hay manera de que usted pueda saberlo".

Por el contrario, el escéptico falso-negativo se denota en frases como éstas:

"Bien podría ser cierto".

"Eso podría comprobarse útil".

"Podríamos saber más de lo que pensamos".

Brevemente, las dos formas de escepticismo pueden resumirse en las siguientes aserciones contrastantes:

El escéptico falso - positivo: "Hay insuficiente evidencia para apoyarlo".

El escéptico falso - negativo: "Hay insuficiente evidencia para rechazarlo".

Hablar de estos dos tipos de escepticismos puede ser algo confuso. Por eso, me referiré también, en el resto de este artículo, al escepticismo falso-positivo como descartador de teorías, ya que ese tipo de escéptico busca razones para rechazar afirmaciones, teorías o interpretaciones; y al falso - negativo, como conservador de teorías, ya que este tipo de escéptico es receloso de la evidencia que pudiera llevar a desaprobar una teoría o a rechazar afirmaciones, interpretaciones o intuiciones.

En las ciencias físicas y sociales, la mayoría de los investigadores se inclinan por una posición escéptica (del tipo) descartadora de teorías; se aplica a minimizar o reducir la posibilidad de hacer errores falso - positivos; es decir, los científicos tradicionales temen cometer el error de afirmar como cierto algo que, en realidad, es falso. Cientos de miles de publicaciones científicas comienzan por la premisa del escepticismo descartador de teorías. Esta práctica ha surgido en respuesta a las observaciones hechas por investigadores, acerca de que nos equivocamos frecuentemente en nuestras intuiciones y de que estamos prontos a aceptar evidencia sospechosa que apoye nuestras teorías favoritas.

En las dos décadas pasadas o algo así, los investigadores médicos han manifestado serios reparos a esta posición científica ortodoxa. La U. S. Food and Drug Administration solía aprobar sólo aquellas drogas que habían comprobado su eficacia (i.e. utilidad) de acuerdo con los criterios de minimización de errores falso-positivos (drogas que podrían haber sido útiles eran rechazadas). El grupo de presión (lobby) del SIDA (Aids) llamó la atención a la falta de lógica de rechazar drogas que parecían prometedoras y que aún no habían sido comprobadas inútiles. Para el paciente que encara una muerte inminente, es el médico ilustrado quien le recomendará buscar los más promitentes de entre los "pseudo remedios" (quacks) recientes ${ }^{8}$. En otras palabras, la comunidad médica ha reclamado una revisión de los posibles efectos dañinos de cometer errores falso - negativos (tipo II). Los escépticos descartadores de teorías son proclives al 
error de afirmar que algo es inútil cuando, de hecho, es útil.

Esta reorientación de las actitudes ha encauzado la investigación médica más cercanamente hacia disposiciones más comúnmente asociadas con la práctica académica de las artes y las humanidades. Hablando en sentido amplio, los académicos tradicionales de las humanidades (incluidos los de las artes) han tendido a temer más la incursión en errores falso - negativos; para muchos de ellos, un temor común es el de rechazar prematuramente una interpretación o teoría que podría tener mérito, a pesar de una evidencia favorable apenas tentativa, tenue o incompleta. Los académicos de las artes, en particular, han apreciado aquello que es mirado como observación sensitiva e intuición: ningún detalle es muy pequeño o insignificante cuando se trata de describir o discutir una obra de arte.

Otro modo en que los académicos tradicionales de las humanidades demuestran tendencias de conservación de teorías se hace evidente en actitudes con respecto a la noción de coincidencia. Para los científicos tradicionales, la meta metodológica principal es la demostración de que las observaciones consignadas no parecen haber surgido por azar. En el paradigma común de Neyman-Pearson para la investigación, esto se logra por la deconfirmación de la hipótesis (llamada) nula al respecto; es decir, el investigador hace un cálculo estadístico que demuestra que los datos observados son inconsistentes con la hipótesis de que tales datos hayan surgido por azar. Para muchos académicos tradicionales de las humanidades, sin embargo, desechar una observación como "una mera coincidencia" es problemático. Si el objetivo es minimizar la presencia de asertos del tipo falso - negativo, entonces una observación aislada "coincidental" no debería dejarse de lado livianamente. Para muchos académicos de artes y humanidades, las aparentes coincidencias son vistas más comúnmente como "armas humeantes".

En suma, tanto los científicos como los humanistas tradicionales están motivadas por el escepticismo, pero, aparentemente, por dos formas diferentes de él. Una de estas comunidades evita aceptar teorías prematuramente; la otra, evita descartarlas. Una repercusión concreta de estas dos formas de escepticismo se puede hallar en actitudes divergentes hacia el lenguaje del reporte académico.

\section{Informes abiertos versus explicaciones cerradas.}

Los científicos son proclives a adoptar la idea de que los académicos humanísticos tradicionales suelen otorgar el beneficio de la duda a hipótesis o interpretaciones interesantes. Señalan que muchos de éstos son, a menudo, escépticos sobre hipótesis científicas para las cuales existe un considerable volumen de evidencia favorable. ¿Cómo, podría preguntarse, puede un humanista dar crédito al concepto de Freud del complejo de Edipo, mientras alberga dudas sobre la veracidad de la teoría de la Evolución de Darwin? Pienso que hay dos respuestas a esta cuestión, una de ellas,

8. Es esencial recomendar pseudodrogas nuevas más que las ya establecidas (como tales). Éstas han sido objetos de investigación que han fallado en probar su eficacia. Las nuevas no comprobadas (aún) tienen una posibilidad mejor de ser útiles. 
substancial, mientras que la otra surge de una comprensible concepción equivocada.

La respuesta substancial tiene que ver con el punto de si una hipótesis dada tiende a excluir otras posibles hipótesis. El complejo edípico podría ser cierto sin excluir significativamente otras ideas o teorías sobre la naturaleza y la interacción humanas. Pero, si la teoría de la evolución es cierta, entonces un gran número de hipótesis alternativas deben ser desechadas. No es, entonces, el caso de que los humanistas mantendrían un doble estándar para la evaluación de hipótesis científicas. Si un académico está motivado por el escepticismo del tipo conservador de teorías (esto es, el que busca evitar afirmaciones falso - negativas), entonces debe distinguir entre teorías excluyentes de cualesquiera otras y las incluyentes o posiblemente coexistentes con otras. El escéptico conserva - teorías puede, en forma lógica, escoger exigir altos estándares de evidencia a una hipótesis dada, precisamente porque proscribe un buen número de interpretaciones alternativas.

Se suele aconsejar a los jóvenes académicos de las humanidades, sacar conclusiones que "se abran hacia afuera" y que "eviten cerrarse". Tal consejo contrasta fuertemente con el que se da a los jóvenes científicos: "la buena investigación distingue entre hipótesis en conflicto". Desde el punto de vista del escéptico del tipo falso-negativo, una explicación "cerrada" aumenta enormemente la posible aparición de errores falso-negativos para las muchas hipótesis alternativas.

Este temor es particularmente dable siempre que el volumen de datos disponibles sea pequeño, como suele ocurrir en las disciplinas humanísticas. Un escaso volumen de evidencia significa que no se espera que ninguna hipótesis triunfe solitariamente sobre las alternativas; por tanto, la expectativa de cerrarse explicativamente en campos pobres en datos debe mirarse como infundada. Así, muchos académicos humanistas miran esa "clausura" como una provocación, un acto político que busca excluir todos los otros puntos de vista.

Desde luego, muchas teorías científicas logran un nivel de evidencia tal que ganan amplia aceptación y rechazo de otras teorías alternativas, pero, aún así, no todos los humanistas estarán convencidos de la justeza de ese rechazo. Sospecho que todos los investigadores (humanistas o científicos) tienden a generalizar, a partir de las experiencias en sus propios campos disciplinarios cuando se responde a trabajos reportados desde otras áreas. Ya que los humanistas trabajan frecuentemente en campos donde la evidencia es escasa, su experiencia reclama que ninguna conclusión o conocimiento puede garantizar la clase de confianza comúnmente expresada por los científicos. Las objeciones a las teorías científicas con base en lo antedicho serían claramente falaces, pero es entendible el que los académicos de disciplinas pobres en datos tiendan a responder escépticamente ante la seguridad altisonante de los otros. Volveremos sobre la consideración de la "clausura" explicativa más adelante, cuando discutiremos la cuchilla de Occam y el problema del reduccionismo.

Habiendo propuesto la asociación entre escepticismo descartador de teorías y la ciencia, por una parte, y el escepticismo conservador de teorías y las humanidades, por otra, retomémoslo y refinémoslo. No pienso que sea una asociación necesaria (en primer lugar). El origen de esta tendencia, propongo, nada tiene que ver con la naturaleza de la academia científica en cuanto opuesta a la humanística; me apresuro 
a decir, también, que un académico dado será escéptico de uno u otro tipo. La gente suele tener una intuición suficientemente buena de cuándo acercarse a un fenómeno como escéptico falso - positivo o falso - negativo.

Si no hay conexión necesaria entre escepticismo descartador de teorías con la ciencia y entre escepticismo conservador de ellas y las humanidades, ¿de dónde provienen tales asociaciones? Creo que hay dos factores contribuyentes de estas disposiciones metodológicas divergentes. Como ya fue sugerido, un factor es la cantidad de evidencia disponible (datos) para la investigación de hipótesis y (la formulación de) teorías; un segundo factor es el de las repercusiones "morales y estéticas" de las hipótesis. Ambos factores se interrelacionan de suerte que se hace difícil discutir sobre cada uno aisladamente del otro; no obstante, trataré de hacerlo en la discusión siguiente.

TEORÍAS DE ALTO Y BAJO RIESGO.

Para el lector común, una de las características distintivas de los resultados investigativos publicados son esas expresiones con graciosas letras griegas y números que adoban frecuentemente la prosa. Se afirman cosas como "X es mayor que $Y$ ", y sigue luego, entre paréntesis, algo de esta guisa:

$$
\mathrm{X} 2=8.32 ; \mathrm{df}=4 ; \mathrm{p}<0.02
$$

Es necesaria cierta destreza para entender estos símbolos, pero el mensaje esencial está en el valor de $\mathrm{p}$.

En inferencia estadística, el valor de p tiene una interpretación más bien complicada; no es un estimativo directo de la probabilidad de incurrir en un error falso-positivo. Sin embargo, si el investigador se propone evitar el reclamo de falsopositivo, entonces esperará ver valores bajos de p. Como hemos visto, según las circunstancias, el investigador podría desear minimizar la posibilidad de hacer un error falso negativo (i.e. se trata de uno conserva-teorías). ¿Cómo sabrá qué tipo de error minimizar? ¿Debería ser escéptico de afirmar positiva o negativamente? ¿Debería buscar conservar o descartar teoría?

La respuesta es que depende de las consecuencias morales (o estéticas) de cometer uno u otro tipo de error. Consideremos, por ejemplo, la diferencia entre casos civiles y penales (criminales) en jurisprudencia. Los casos civiles (v.gr. invasión) requieren evidencias comparativamente modestas para asegurar una condena ("preponderancia de evidencia"). Los casos criminales (v. gr. asesinato) requieren evidencia mucho más convincente ("más allá de la duda razonable"). Estos diferentes estándares de evidencia deben observarse por causa de las diferentes repercusiones morales de incurrir en un error falso positivo. Asegurar la condena de un inocente en un juicio de asesinato es una grave equivocación comparada con la de la invasión de propiedad privada.

Campos de pesquisa que comportan riesgos significativos (como medicina, jurisprudencia y salud pública) deberían tener altos estándares de confianza. Si el 
campo es rico en datos, es especialmente importante recoger un volumen suficiente de evidencia para que el investigador pueda integrar un caso convincente. Si el campo fuera pobre en datos, como ocurre a menudo con la jurisprudencia, entonces uno puede esperar la incursión en muchos errores y las repercusiones morales de un error falso-positivo versus uno falso-negativo determinarán si el investigador adoptará un escepticismo conservador o descartador de teoría. En Derecho penal, pueden esperarse muchas fallas en condenar gente culpable con el fin de minimizar el número de condenas injustas.

En contraste con los procesos criminales, la mayoría de las hipótesis académicas tiene riesgos morales o estéticos marginales. Por ejemplo, la verdad o falsedad de una teoría sobre los orígenes del arte románico tiene pocas consecuencias morales, aunque el riesgo no está siempre enteramente ausente. Supongamos que un musicólogo encuentra evidencia que sugiere que un compositor ha plagiado una melodía de otro. Si el dictamen de plagio fuera falso, la reputación del primero resultaría injustamente manchada y si estuviera vivo todavía, esa falsa afirmación sería moralmente reprensible.

Para el estadístico sazonado, nada nuevo hay en esta discusión porque él siempre ha entendido las relaciones recíprocas entre errores falso-positivos y negativos y reconocido que la aplicación del investigador a reducir un tipo de error u otro depende enteramente de los riesgos implícitos en ello. En casi todas las artes y humanidades, cometer un error falso-positivo raramente tiene repercusiones morales o estéticas; pero afirmaciones falso-negativas han sido vistas muchas veces como irresponsables.

Probablemente, el argumento conserva-teorías mejor conocido es el de la apuesta de Pascal. No convencido por las muchas pruebas ofrecidas de la existencia de Dios, Pascal se preguntó qué se perdería si la proposición fuera verdadera pero la evidencia escasa. Arguyó que las repercusiones de cometer un error falso-negativo (en ese caso) eran muy onerosas. Escogió entonces creer en Dios, nó porque la evidencia positiva fuese determinante sino porque pensó que el riesgo moral asociado con un rechazo erróneo de tal hipótesis requeriría un volumen extraordinario de evidencia en contrario (Pascal, 1669).

Históricamente, las pruebas estadísticas se han usado casi exclusivamente para minimizar la ocurrencia de errores falso - positivos. La comunidad de los escépticos descarta-teorías es la que ha hecho mayor uso de la estadística. Sospecho que esta asociación histórica entre el uso de la inferencia estadística y el escepticismo falsopositivo puede explicar mucho acerca de la sospecha ampliamente difundida entre los académicos de las artes y las humanidades, acerca de los argumentos estadísticos. Sin embargo, nada hay en la inferencia estadística per se que sea contrario a la tendencia de los humanistas al escepticismo falso-negativo, como bien lo saben los estadísticos.

Como ya se dijo, las asociaciones de ciencia con falso-positivo y de humanidades con falso - negativo están cambiando. La medicina contemporánea ha llegado a entender los peligros del descarte prematuro de teorías y, concurrentemente, muchos investigadores humanistas (sociales) están ahora más concientes de los (posibles) problemas del escepticismo falso-negativo. En cuanto a la música, varios cientos de años de teorización especulativa han llevado a la promulgación de innumerables 
ideas, muchas de las cuales seguramente carecen de fondo. Hasta hace poco, era poco lo que podía hacerse al respecto. La escasez de datos pertinentes en muchos campos de las humanidades simplemente hacía imposible satisfacer criterios estadísticos que minimizaran posibles errores falso-positivos. Las oportunidades de resolver estos problemas han crecido inmensamente, debido a la creciente disponibilidad de bases de datos en el computador, herramientas referenciales comprehensivas y el uso creciente de colecciones de datos surgidos de la experimentación. Volveremos a estos asuntos más adelante.

\section{LOS CAMPOS HISTÓRICOS.}

Los campos pueden distinguirse (entre otros criterios) de acuerdo con si la principal evidencia o conjunto de datos surgen del pasado o del futuro. Los campos históricos son aquéllos cuyos datos fundamentales ya existen. La arqueología, la paleontología y la historia del arte son ejemplos de campos históricos. En cada uno de éstos, los fenómenos principales de estudio ocurrieron en el pasado. Tales fenómenos son accesibles al estudioso sólo mediante las tenues huellas de datos que existen ahora, que pueden incluir documentos en papel, objetos físicos, historias orales o memorias inexpresadas. Por norma general, la evidencia existente integra un subconjunto propio de toda la evidencia alcanzable, mucha de la cual ha sido destruida por el paso del tiempo.

Es un error pensar que los campos históricos pertenecen, sobretodo, a las humanidades. Las ciencias de la astronomía, la geología y la paleoantropología son campos predominantemente históricos. Cada una de ellas se basa, primariamente, en evidencias de acontecimientos pasados. Indudablemente, la disciplina histórica preeminente, podría argüírse, es la astronomía: la luz que alcanza los telescopios astronómicos tiene una edad, típicamente, de millones de años luz. Es raro que los astrónomos puedan hablar de estudiar "eventos corrientes" (actuales).

\section{DATOS RETROSPECTIVOS VERSUS DATOS PROSPECTIVOS.}

Los datos históricos no deben confundirse con los que pudieran llamarse retrospectivos. Éstos son evidencia que ya está disponible y que es conocida por el investigador. Por contraste, los datos prospectivos son aquéllos aún no disponibles para él y que incluyen evidencia que se recogerá en el futuro o que el investigador aún no ha visto (por ejemplo, datos publicados en un artículo ahora olvidado o manuscritos que reposan en un archivo por el que se ha pasado de largo).

Noté que los datos prospectivos pueden ser enteramente históricos, como en el caso de las predicciones meteorológicas. Normalmente pensamos que los meteorólogos comprueban sus modelos prediciendo el tiempo futuro, del día de mañana, de la semana entrante o del año próximo. Sin embargo, las más de las teorías meteorológicas son comprobadas usando datos históricos (pasados).

Del mismo modo, suponga que un etnomusicólogo formula una teoría basada en 
el estudio de tres sociedades de recolectores-cazadores; podría teorizar, por ejemplo, que, si una comunidad de éstas es matrilineal, emplea líneas melódicas preferiblemente ascendentesmientrasqueunapatrilineal,melodíaspreponderantementedescendentes. Tal teoría podría comprobarse prediciendo patrones culturales como ésos en otras comunidades de recolectores-cazadores y comprobando tales predicciones en nuevas investigaciones de campo entre culturas aún no estudiadas. Pero también podríamos comprobar las predicciones comparándolas con datos ya existentes acerca de otras sociedades, provisto que esos datos sean prospectivos más que retrospectivos. De manera semejante, los historiadores pueden comprobar teorías específicas por medio de la predicción de contenidos de documentos recientemente descubiertos, ojalá aún cerrados (ocultos), sobre un acontecimiento particular histórico.

En algunas áreas del conocimiento, todos los datos pertinentes están ya disponibles: ninguna cantidad de dinero aumentará, necesariamente, el volumen de documentos relativos a la vida de Petrarca, es decir, todos los datos son retrospectivos y los investigadores tienen poca esperanza de hallar datos prospectivos. La pérdida de oportunidades para hacer hallazgos de datos prospectivos implica la imposibilidad de evaluar una teoría por la comprobación de predicciones y esa situación tiene repercusiones onerosas para la investigación del área cognitiva así afectada.

\section{TEORÍAS PRE-DATOS Y DE POST-DATOS.}

Uno de los problemas más perniciosos que plaga las disciplinas históricas es la tendencia a usar un mismo conjunto de datos, tanto para generar la teoría (hipótesis) como para comprobarla. Formalmente, si la observación 0 es usada para formular la teoría T, entonces $\mathrm{O}$ no puede forzarse como resultado predicho de T. Es decir, $\mathrm{O}$ no comprueba T.

El origen de la teoría de la deriva de los continentes surgió de la observación de la sospechosa correspondencia visual entre las costas de los continentes americanos y las costas occidentales de Europa y África. El contorno del África noroccidental parece ajustarse como pieza de rompecabezas en el golfo caribeño. Esta observación fue ridiculizada como un sinsentido infantil por algunos geólogos en la primera parte del siglo XX. Tuvieron razón en descartar la similitud de los contornos de costas como evidencia para comprobar la deriva continental, ya que tal semejanza fué la que dió origen a la teoría. La tectónica de placas ganó credibilidad sólo cuando se reunieron evidencias independientes, consistentes con la dispersión del lecho atlántico.

Tal teorización "post hoc" ha plagado especialmente (el campo de) las teorías evolutivas (Ver Gould, 1978; Gould y Lewontin, 1979; Rosen, 1982). No obstante, en ciertos casos, pueden surgir teorías evolutivas que hacen predicciones acerca de datos aún sin recoger (como la hipótesis Trivers-Willard). Las buenas teorías son apriorísticas; es decir, sugieren o predicen ciertos hechos o fenómenos antes de ser certificados u observados.

Campos que dependen exclusivamente de datos retrospectivos son proclives a la teorización "post hoc", pues las hipótesis se forman fácilmente, pero se comprueban difícilmente. Se trata de un problema endémico en varios campos, especialmente en 
los históricos, la astronomía incluida; lo que no obsta para que una cuidadosa atención a la lógica subyacente de una teoría pueda permitir la comprobación de predicciones inesperadas de datos prospectivos preexistentes. La astronomía y la biología evolutiva han demostrado que hay muchas más oportunidades de comprobación de teorías históricas que las que reconocen los historiadores que laboran en las disciplinas humanísticas.

\section{DATOS EXPERIMENTALES VERUS CORRELATIVOS.}

Una ulterior distinción puede hacerse entre dos tipos de datos prospectivos, pues cuando se hacen predicciones acerca de ellos, puede distinguirse entre fenómenos que pueden ser influidos por el investigador y aquéllos que están más allá de su posible influencia. En algunos casos, como en la predicción meteorológica, los investigadores tienen poca o nula posibilidad de manipular las condiciones iniciales y observar sus consecuencias. En otros, pueden iniciar fenómenos por sí mismos, crear o influir las condiciones iniciales o contexto de algún fenómeno y observar las consecuencias causadas.

Las disciplinas en las que se pueden influir o nó los fenómenos estudiados dan lugar a metodologías diferentes. Cuando es posible una significativa interacción con el fenómeno, los estudiosos pueden realizar experimentos formales; por ejemplo, un psico-musicólogo puede manipular directamente el timbre de un sonido y determinar si los oyentes de diferentes culturas perciben ese sonido como "más bello" o "menos bello". La manipulación de variables únicas en un experimento, permite al investigador inferir causalidad: un experimento diestramente diseñado permite demostrar que A afectó a B, más que B haber afectado a A. Por contraste, los historiadores no pueden realizar experimentos controlados. No hay forma de volver al pasado para cambiar una única variable ni de construir un mundo independiente y observar los efectos de manipulaciones específicas. En la jerga de la metodología empírica, las disciplinas históricas dependen, necesariamente, de métodos correlatores más que experimentadores.

En los estudios correlatores, el investigador puede demostrar que hay una relaciónasociación entre dos variables o acontecimientos; pero no hay manera de determinar si A causa B o si B causa A, aunque no puede descartarse que estén causalmente conexas; podría ser también que A y B sean causadas por una tercera variable independiente. Como ilustración, podríamos notar que, cuando hay un aumento en el consumo de helados, siempre hay un aumento concomitante en las muertes por ahogamiento y viceversa. Claro está que una razón posible (imaginable) para tal correlación es que los días calientes del verano llevan a que la gente vaya a nadar y, también, a que consuman helados. En las disciplinas históricas, jamás se puede saber si la asociación de dos fenómenos es causal, accidental o efecto de un tercer factor.

\section{RIQUEZA Y POBREZA EN DATOS.}

De todas las distinciones taxonómicas hechas en este artículo, la distinción entre áreas 
de investigación ricas y pobres en datos es, probablemente, la más seminal. Aunque la palabra data (datos, plural de datum) infortunadamante implica algo científico, intentemos tomar el término en el sentido más amplio posible, de información, observación, artefacto o evidencia que pueda ser pertinente para una teoría, hipótesis, interpretación o intuición.

Las disciplinas ricas en datos pueden, principalmente, descubrir o reunir tanta información, evidencia, observaciones, etc. como deseen, siendo los recursos económicos la única limitante. Las disciplinas pobres en datos tienen pobre control sobre el volumen de datos pertinentes: Como ya se anotó, ninguna suma de dinero aumentará, necesariamente, la cantidad de documentos relativos a la vida de una (cierta) figura histórica.

Hay cuatro modos en que un área puede ser pobre en datos. Uno es que el fenómeno mismo sea comparativamente raro; es difícil estudiar fenómenos como el rayo redondo, los verbos monosílabos vocal-consonante, los tigres de Bengala blancos o el desorden de personalidad múltiple. Pocos musicólogos históricos experimentarán el estremecimiento de descubrir un manuscrito de una obra desconocida de un gran compositor.

Un segundo modo ocurre cuando los datos son volátiles o se destruyen rápidamente. Para el paleontólogo, los tejidos corporales blandos desaparecen en cuestión de años y son difíciles de estudiar a partir de muestras de roca fósil. Algunas partículas subatómicas existen durante menos de una millonésima de segundo. Para el psico-musicólogo, las experiencias musicales de un oyente, momento por momento, son efímeras y evanescentes.

Un campo puede ser pobre en datos porque éstos son inaccesibles. Los datos arqueológicos son desgastados por diversos materiales; se supone que los neutrinos están por doquier en grandes cantidades, pero no tienen carga eléctrica ni masa, por lo que se resisten a la interacción mediante aparatos electrónicos. Aunque se realizan cientos de miles de grabaciones aficionadas cada año, los musicólogos las encuentran de difícil estudio: ¿cómo pueden reunirse las grabaciones de obras de Bach para clave, tocadas por aficionados en un año dado?

Finalmente, los datos pueden haberse perdido, simplemente. La destrucción de la famosa antigua biblioteca de Alejandría transformó la filosofía presocrática en un campo notoriamente pobre en datos. Una traducción de todos los textos presocráticos sobrevivientes se remonta a escasas 162 páginas (en inglés: Fitt, 1959). Esto incluye los textos completos accesibles de lo escrito por Pitágoras, Tales, Anaximandro y docenas de otros pensadores clásicos. Los ejemplos musicales abundan: no queda una sola traza del Requiem de Dufay, v.gr.

\section{LA FALACIA DEL POSITIVISTA.}

Los campos pobres en datos enfrentan algunos problemas metodológicos; uno de ellos es el conocido como "falacia del positivista". Si un fenómeno no deja rastro de evidencia, entonces nada hay por estudiar. Incluso, podríamos estar tentados a concluir que nada ha sucedido. Dicho de otra manera, tal falacia consiste en confundir 
la ausencia de evidencia con la evidencia de la ausencia.

El positivismo ejerció una marcada influencia en la psicología estadounidense de mediados del siglo veinte, en particular, del positivismo lógico sobre los conductistas como J. B. Watson y B. F. Skinner. Ejemplo clásico de la falacia del positivista fué la pretensión de rechazar estados mentales inobservables, como no existentes. Por ejemplo: en vista de que la "conciencia" no era observable, (entonces) para el positivista, ésta debía ser mirada como una cualidad oculta o ficticia sin status de verdad (Ayer, 1936).

Si bien es cierto que la falacia del positivista tiende a surgir de condiciones de pobreza en datos, entonces debería ser posible observar este mismo error de concepto en la academia humanística cuando los datos sean escasos. Consideremos, por manera de ejemplo, el siguiente argumento del distinguido musicólogo histórico Albert Seay. Al comienzo de su, por otra parte, fino libro sobre la música medieval, Seay provee la siguiente razón para concentrarse predominantemente en la música sagrada por sobre la secular: "Aunque existió bastante música para propósitos seculares y muchos músicos satisficieron las necesidades de las audiencias seculares, la iglesia y sus oportunidades musicales permanecieron como preocupación central. No puede hallarse mejor evidencia del énfasis sobre lo religioso que en la relativa escasez, tanto de información cuanto de materiales-fuente para la música secular en comparación con los de la sagrada" (Seay, 1975, pág. 2). En otras palabras, el autor arguye que, con respecto al hacer musical secular, la ausencia de evidencia es evidencia de ausencia. Puesto que las actividades seculares generaban poca documentación, casi no tenemos idea del monto y de la ocurrencia diaria del hacer musical secular del Medioevo. Para los campesinos analfabetas, la música folclórica hecha por cada uno debe haber moldeado la experiencia musical diaria mucho más de lo que se ha supuesto. Obviamente, Seay debe tener completa razón en cuanto a la poca importancia de la práctica musical secular de entonces; pero, al basar su argumento en la ausencia de datos, está en compañía de los más rabiosos positivistas lógicos. La falacia del positivista es mirada comúnmente como un síntoma de exceso científico; sin embargo, no conoce fronteras disciplinarias y tiende a aparecer por dondequiera los datos sean escasos.

\section{PARSIMONIA VERSUS PLURALISMO.}

Un precursor intelectual importante del positivismo lógico puede encontrarse en la navaja de Occam. Guillermo de Occam (Ockham) promovió la idea de que el número de factores incluidos en una explicación no deberían multiplicarse más allá de los necesarios. Los filósofos modernos se refieren a esto como el principio de la parsimonia, vale decir, que uno debería preferir la hipótesis más simple que pueda dar cuenta de la evidencia observada. Los conceptos, factores o causas no esenciales deberían descartarse.

Desde luego, la explicación más simple puede no ser la correcta9 ${ }^{9}$. Los biólogos, en especial, han descubierto que los procesos fisiológicos, típicamente son mucho más complejos de lo que parecería necesario. De todas maneras, hay mérito metodológico en la exclusión de complejidades innecesarias. Cada vez que un factor o parámetro 
adicional se introduce, la probabilidad de errores falso-positivos se incrementa.

Limitar el número de parámetros o factores disminuye dramáticamente la posibilidad de construir una explicación o modelo espurio; para el escéptico falsopositivo, la esencia de la parsimonia tiene mérito, nó porque reduzca los fenómenos complejos a simples, sino porque la reducción de variables disminuye el riesgo de incurrir en errores falso-positivos. En cambio, aumentar el número de factores contribuyentes puede hacer un modelo más realístico, pero, lamentablemente, también aumenta la probabilidad de autodecepción.

\section{Tres caras del reduccionismo.}

Hay tres maneras, por lo menos, de interpretar el término "reduccionismo": a) Una es adoptar la norma metodológica de usar el menor número posible de variables para la formulación de una teoría, una concepción equivalente al principio de parsimonia que ya hemos discutido ${ }^{10}$; b) una segunda manera de entender el reduccionismo es el método investigativo "divíde y vencerás"; c) Una tercera manera es la del modo explicativo "nada más que". Estas dos últimas concepciones del reduccionismo son las que explicaremos enseguida.

El reduccionismo del tipo "divíde y vencerás" se aplica a elucidar fenómenos complejos aislando relaciones constitutivas. Clásicamente, la principal herramienta utilizada es el concepto de "control", consistente en mantener constantes uno o dos factores mientras la "variable independiente" es manipuladay la "variable dependiente" es observada; también se aplica escogiendo las variables potencialmente confusoras al azar. Para tomar una encuesta política, por ejemplo, los encuestadores tienen la expectativa de que el número de variables influyentes sobre una determinada opinión es muy grande y no cabe asumir que uno pueda mantener constantes un gran número de factores. En consecuencia, los investigadores realizan un muestreo al azar con la esperanza de que influencias desconocidas tiendan a cancelarse unas con otras.

El argumento estadístico formal que apoya el muestreo al azar es bastante convincente y se suele otorgar, entonces, mérito (más o menos universal) a este método de control, que hace posible investigar el efecto de un factor dado en un fenómeno complejo. Investigando un factor a la vez, es posible, frecuentemente, construir un modelo sofisticado o teoría de dicho fenómeno. Cuando el número de factores es superior a 5 o 6, la estrategia del "divíde y vencerás" suele ser inaplicable, debido a la explosión de posibles interacciones entre los factores involucrados, aunque podría todavía ayudar a identificar importantes relaciones en los fenómenos del mundo real.

La forma de reduccionismo más discutible podría llamarse la manera de explicación "nada más que". Ese reduccionista trata de explicar fenómenos complejos como, simplemente, la interacción de otros más simples subyacentes, o sea de enteros complejos en términos de componentes más sencillos, mediante una formulación del tenor siguiente: $\mathrm{X}$ no es otra cosa que $\mathrm{Y}^{\prime \prime}$.

9. "En las interpretaciones musicales, la complejidad es mérito...en las ciencias sociales, parece que la complejidad se evitara: los detalles de los fenómenos se descartan para que las conclusiones puedan ser expresadas del modo más simple posible” (Rahn, 1983; p. 197). 
En tal sentido, el reduccionismo contrasta con el llamado "holismo" (integrismo). Un integrista espera explicar un fenómeno como algo que es más que la suma de sus partes (un proceso llamado "sinergismo" por Buckminster Fuller). Con frecuencia, el sinergismo predica (la aparición de) "propiedades emergentes" en los casos en que fenómenos complejos no pueden predecirse a pesar del entendimiento exhaustivo de los fenómenos constituyentes del mismo.

En contraste con el integrista, el reduccionista del tipo "nada más que" busca explicar todos los fenómenos complejos como manifestaciones convulsas de un puñado de causas o interacciones fundamentales: (para ellos) la cultura es sociología, ésta es simple psicología, la psicología es pura biología; ésta, química y ésta última, física.

No puede uno menos que estar impresionado por la grandiosidad de tal programa (idea). Si fuera verdadera una tal síntesis científica reductiva, ella representaría uno de los logros pinaculares del saber humano; si fuera falsa, sería una de las más eminentes estupideces en la historia humana.

Académicos humanistas de muchas franjas intelectuales han hecho mofa del proyecto reduccionista. Gran parte de las objeciones se originan en las repercusiones estéticas "insípidas" de ese "nada más que". Se arguye que esas explicaciones reduccionistas, explican sólo en el sentido de hacer plano (llano, ex plano). El mundo, como lugar encantador, se transforma en una empresa prosaica, incolora e insípida, sin sentido. Entre los académicos humanistas (y sociales), los músicos y musicólogos se han contado entre los vocales más críticos del reduccionismo del tipo "nada más que". Los teóricos musicales, en forma explícita, prefieren la complejidad y desprecian la simplicidad. John Cage previno con fuerza contra las "minimizaciones lógicas". Más aún, previó que esta tendencia reductiva no se limitaría a las ciencias. Sorprende saber dónde puede uno encontrar el reduccionismo "nada más que".

Consideremos, una vez más, el postmodernismo. La filosofía postmodernistadeconstruccionista aboga por la develación de conceptos y expresiones en términos de papeles socialmente construídos y relaciones de poder (e.g. Hacking, 1995); (así) ha ayudado a exponer maneras sutiles, y otras no tan sutiles, en que el discurso ostensiblemente racional manifiesta formas de dominio y control; pero el postmodernismo va más allá. Los principios más abstractos de leyes, filosofía y aún ciencia se entienden mejor desde el punto de vista político: todo se reduce a ello Nótese que, en esta formulación, postmodernismo y deconstruccionismo llevan todos los signos del reduccionismo "nada más que". Cualquier pensamiento que uno tenga cuidado de expresar puede ser reducidoa un motivo político, tanto como un sociobiólogo puede creer que un fenómeno social es, finalmente, reducible a interacciones químicas subyacentes y como el postmodernista exacerba su reduccionismo viendo cualquier discurso científico como manifestación de estratagemas de poder. Igual que en el caso de la síntesis científica reductiva, no puede uno menos que impresionarse con la grandiosidad, que (nos) deja sin aliento, de estos patrones explicativos postmodernos.

Sugeriríamos que hay una manera más útil de entender el valor del reduccionismo y evitar, al tiempo, algunos de (sus) más inedibles excesos, tanto en las ciencias como en las Humanidades. Una buena distinción es tratar el reduccionismo como una 
estrategia útil para el descubrimiento más que como una creencia acerca de cómo es el mundo. En concreto, el postmodernista podría asumir la parsimonia como una técnica para ayudar a distinguir un comportamiento complejo; en forma parecida, el sociobiólogo podría asumir un gene recesivo como técnica para ayudar a analizar un rasgo de la personalidad. En ambos casos, es peligroso concluir que la herramienta es la realidad, pero queda la posibilidad de que el principio reductivo explicativo se pruebe útil en la intelección del fenómeno en cuestión.

\section{Creencias humanísticas y mecanicistas.}

Nuestra comprensión del reduccionismo puede ser ayudada por la contrastación entre los términos reduccionismo e Integrismo (Holism) y la distinción filosófica entre visiones humanísticas y mecanicistas. Estos últimos conceptos pueden caracterizarse así:

- Humanísticos: los que provienen de la creencia en el espíritu y la conciencia como fundamentales y no reducibles a descripciones mecánicas.

- Mecanísticos: provenientes de la creencia en una concepción mecánica de vida y conciencia y en que nada hay misterioso o enigmático en ellas sino sólo nuestra ignorancia de cómo funcionan las cosas.

De acuerdo con estas definiciones, humanismo y mecanismo son creencias, mientras reduccionismo e integrismo, como han sido caracterizados aquí, son puntos de vista o criterios metodológicos. Cierto es que los investigadores que sostienen un punto de vista mecanicista tienden a preferir métodos reduccionistas y que quienes mantienen una visión humanística tienden a abogar por métodos integristas. Sin embargo, no hay una conexión necesaria entre humanismo y holismo ni entre mecanicismo y reduccionismo. Hay muchos científicos (especialmente aquéllos que trabajan en áreas de complejidad y caos) que mantienen un punto de vista mecanicista del mundo, pero presumen que complejas interacciones pueden llevar a propiedades emergentes que no pueden predecirse (e.g., Anderson, 1972; Gell-Mann, 1994; Gleick, 1987; Pagels, 1988). Además, un investigador puede, convencidamente, defender una visión humanística de los orígenes del comportamiento humano y confiar en el reduccionismo como método investigativo útil. Vale decir que no es necesario creer que la conducta humana sea mecanística para usar el reduccionismo como modo de comprobar las complejidades del mundo. Usar el reduccionismo como estrategia no implica un punto de vista mecanístico en el estudioso. Del mismo modo, analizar un fenómeno como una propiedad integrista emergente no transforma, por ello, al investigador en un espiritualista.

\section{El papel de lo cuantitativo.}

Antes dijimos que "empirismo" significa, simplemente, conocimiento ganado mediante la observación. Para muchos críticos del empirismo, no es la idea del conocimiento 
por la observación per se el que genera preocupación, sino la difundida confianza (y fundamentación) del empirismo en los métodos cuantitativos.

Tal vez la sospecha principal es la de que los métodos cuantitativos fuerzan los fenómenos a pertenecer a categorías numéricas que podrían ser o nó apropiadas. Un investigador, por ejemplo, podría requerir a unos oyentes a situar ejemplos musicales en una escala de 1 a 10, donde 1 representa "máxima tristeza" y 10, "máxima alegría", lo que se prestaría a múltiples objeciones: la alegría y la tristeza pueden ser fenómenos que no existan en algún tipo de continuo unificado; el ejemplo musical podría no mantener un carácter consistente durante todo el pasaje; una parte "conmovedora" de él podría ser tanto triste como alegre simultáneamente; o podría ser reconocible en su intento de retratar la felicidad, aunque un determinado oyente podría encontrar el retrato como no convincente y, por tanto, "triste", es decir, como un error; los juicios numéricos podrían ser ininterpretables: ¿es el valor 2 entendible como el doble de triste que 1 ? y así sucesivamente.

Problemas como éstos forman, en efecto, mucha parte del currículo fundamental en el entrenamiento para la metodología cuantitativa; por ejemplo, los empiristas aprenden que cualquier escala de juicios debería siempre usar un único adjetivo ("de mínimo X a máximo X" y nó "de máximo X a máximo Y"). De la misma manera, aprenden que las mediciones jamás deben interpretarse como índices directos de fenómenos reales y que las definiciones operacionales no deben ser reificadas (cosificadas). Los estadísticos han diseñado procedimientos analíticos completamente independientes, según las propiedades de varias escalas de medida.

Para muchos académicos de inclinación humanística, sin embargo, algo inherentemente erróneo yace en la cuantificación de las experiencias humanas, especialmente aquéllas relativas a las relaciones, la estética y la vida espiritual. Muchos de ellos estarían de acuerdo con Renato Pogioli cuando afirma que lo técnico y cuantitativo tienen su lugar pero nó en las artes: "el (vocablo) 'tecnicismo' significa que el genio técnico invade los dominios espirituales, donde la técnica no tiene 'raison d'etre' ...no es contra la técnica o la máquina contra las que el espíritu se rebela con justicia, sino contra esa reducción de valores inmateriales a las categorías brutas de lo mecánico y lo técnico..." (pág. 138).

Una vez más, respondámos a esta opinión distinguiendo entre las metodologías de la pesquisa académica y las creencias filosóficas acerca de la naturaleza del mundo. Si esta distinción fuere hallada demasiado abstracta, consideremos la siguiente ilustración bien conocida, que hace un paralelo entre actitudes acerca del uso de la escritura y de la notación musical.

Se sabe que Sócrates criticaba la invención de la escritura. Correctamente, señalaba un número de consecuencias predecibles y cuestionables de depender de textos escritos; especialmente, predijo la declinación en la importancia de la memoria y en las capacidades oratorias, predicciones que se han comprobado como ampliamente ciertas. Pocos niños modernos pueden recitar más de un poema; los políticos dependen de las pantallas (teleprompters) y los académicos de las humanidades hacen presentaciones públicas con sus cabezas inmersas en densos textos que dejan a sus 
oyentes en confusión. A pesar de las legítimas predicciones socráticas, la escritura ganó la partida. De hecho, fué reconocida prontamente como proveedora de invaluables ventanas sobre fenómenos anteriormente desconocidos; con la escritura, por ejemplo, los griegos descubrieron la gramática; al convertir el habla en no efímera, los antiguos descubrieron las partes del discurso (substantivos, adjetivos, verbos...) y tiempos, conjugaciones, frases, proposiciones y otras estructuras. En suma, la invención de la escritura proveyó una oportunidad sin precedentes de entender mejor el lenguaje y, paradójicamente, el habla misma.

Una historia casi idéntica ocurrió con el advenimiento (y desarrollo) de la notación musical. La teorización era común ya desde mucho antes de que la música se escribiera; pero aquélla inspiró, incuestionablemente, y facilitó, el crecimiento de la teorización musical en Occidente. Como en el caso del lenguaje escrito, la notación de la música permitió a los musicólogos la identificación de patrones de organización que, de otra manera, hubiesen sido difíciles o imposibles de discernir.

Claro que, como con Sócrates, la notación ha atraído sus propias críticas. Es probable que los músicos dedicados al Jazz resuenen con las observaciones de un viajero árabe por Europa, el señor Faris al-Shidyaq: "Los francos (europeos) no tienen música 'libre' que no esté amarrada a sus signos gráficos...si usted sugiere a uno de ellos que cante un par de líneas 'ex tempore' no podrá hacerlo. Es extraño, si consideramos su excelencia en este arte, ya que el cantar así es natural y estuvo en boga entre ellos antes de la existencia de estos signos y símbolos gráficos..." (como aparece citado en Nettl, 1985, pág. 123, trad. G.Y.).

Una consecuencia quizás infortunada de la notación musical ha sido la reificación de las notas como música. La palabra misma (música) ha adquirido hoy en día significados que habrían confundido a los músicos antiguos. En los tiempos que corren, es posible que la "música" se caiga de los atriles o que sea ingerida por el perro de uno. Consideremos la bien conocida concepción del filósofo Nelson Goodman sobre la identidad de la obra musical: "una partitura, sea usada o nó alguna vez como guía para la ejecución, tiene una función primaria como identificación autorizada de la obra entre una y otra ejecuciones. Frecuentemente, partituras y notaciones -y pseudopartituras y pseudonotaciones- tienen otras funciones más excitantes como facilitadoras de la transposición, de la comprensión y, aún, de la composición; pero cada partitura, en cuanto tal, tiene el cometido, lógicamente anterior, de identificar la obra." (Goodman, 1976/1981, pág. 128, trad. G.Y.).

Según Goodman, la noción de la existencia de un trabajo musical carente de partitura es un asunto filosófico complejo y tortuoso; la identidad misma de la "música" está íntimamente ligada y equiparada con los artefactos materiales notacionales de una cierta clase y esto es lo que es significado por la palabra "reificación".

Como en el caso del lenguaje escrito y de la notación, los métodos cuantitativos proveen importantes oportunidades de detectar patrones de organización invisibles de otra manera y, al tiempo, ocasiones para la reificación y el fetichismo. Las actitudes académicas hacia la notación están mezcladas con razón: las notas han deparado medios extraordinarios para la pesquisa académica, pero, también, han propiciado 
la aparición de creencias debatibles y cuestionables sobre la naturaleza del mundo musical.

Si aplicamos métodos cuantitativos en la investigación musical, debemos estar bien lejos de cualquier exceso. La academia musical, más bien, apenas ha comenzado a tomar ventaja de las genuinas oportunidades disponibles para entender mejor la organización de la música. De los muchos ejemplos que pueden usarse para ilustrar la pertinencia de métodos empíricos cuantitativos, dos deberían bastar: los relativos a los conceptos de "arco melódico" y de "llenado del espacio vacío".

\section{EL ARCO MELÓDICO.}

Por siglos, los teóricos musicales han llamado la atención sobre el llamado "arco musical”, una presunta tendencia general de las frases melódicas a ascender y luego descender. Sin embargo, hay cantidades de contraejemplos; muchas melodías exhiben frases iniciales convexas, que comienzan descendiendo.

¿Qué debería pensarse de tal arco melódico? ¿Hay esa tendencia general o será que los autores de los textos han sido selectivos en sus ejemplos?

Este autor realizó un estudio que involucraba más de 36,000 frases melódicas tomadas de cantos folclóricos de Europa; lo primero que habría que resolver es la definición de "arco". Una manera de hacerlo es que éste se da cuando todas las notas (sonidos) van hacia arriba en entonación (frecuencia) en la primera mitad de la frase, mientras, en la segunda mitad, se mueven hacia abajo. Una definición menos restrictiva podría requerir, simplemente, que la altura promedio de los sonidos inicial y final de una frase sea más baja que la de los intermedios. Adicionalmente, uno podría determinar los contornos de frase sólo una vez que los sonidos no esenciales han sido descartados. Sin haber resuelto el asunto de lo que se entiende por arco, el estudio usó diferentes definiciones operativas y halló los mismos resultados, mediante el análisis de 6,364 frases promediadas de siete sonidos, sin importar cómo se definiese un arco; es decir, todas las nociones alternativas de "arco melódico" convergían en la misma respuesta.

Aunque hay muchas frases individuales que no muestran una forma de arco, la gran mayoría tiene un indudable contorno ascendente-descendente. Los resultados son, entonces, consistentes con la idea teórica general del arco melódico, al menos en las melodías folclóricas occidentales. Podría suponerse que promediar miles de frases melódicas es el epítome de la lunaticidad cuantitativa, pero algunos procedimientos cuantitativos simples pueden resultar significativamente útiles para encarar ciertas clases de problemas musicales.

\section{LLENADO DE ESPACIOS VACÍOS.}

Una crítica común de los estudios empíricos en música es que confirman meramente nuestras intuiciones. Un buen contraejemplo se provee con el fenómeno del "Ilenado de espacios vacíos". Durante 500 años, académicos musicales han observado que los grandes saltos melódicos tienden a ser seguidos por cambios en la dirección melódica. 
Hay para ello una variedad de nombres, pero usemos la terminología de Leonard Meyer: "llenado de vacíos" (Gap fill).

En un conjunto de estudios, Paul von Hippel (Von Hippel y Huron, 2000) realizaron extensas investigaciones empíricas sobre ese concepto. Los resultados no son del todo consistentes con las intuiciones teóricas acerca del asunto en cuestión. La historia tiene dos partes:

(1) Sin duda, la mayoría de intervalos grandes tienden a ser seguidos por un cambio en la dirección melódica y este patrón ocurre en melodías de los cinco continentes y por 500 años, tanto para respuestas inmediatas como para las postergadas.

Sin embargo...

(2) Si usted "revolviera" completamente el orden de los sonidos dentro de una melodía,

(3) terminaría con melodías "al azar" (random) que tienden a tener exactamente la misma cantidad de llenado de vacío que las melodías originales mismas, también para ejemplos de los cinco continentes y por 500 años.

El hecho de que versiones revueltas (al azar) de las mismas melodías produzcan la misma tendencia al llenado de vacío, sugiere que no se trata de una consecuencia intencional de la composición.

Hay una explicación llana de por qué ocurre así y es un fenómeno estadístico llamado "regresión a la media"11. Un gran salto tenderá a llevar la melodía hacia los límites superior o inferior del rango melódico. Habiendo alcanzado, digamos, un sitio cercano al borde superior, la melodía tiene poca oportunidad de hacer algo distinto a continuar con uno de los sonidos más bajos que tal límite. En la música real, mientras más cerca esté el salto a los extremos del rango, más probable será que el contorno melódico cambie de dirección. Si un salto llega a un sitio cercano al medio de la tessitura, el cambio de dirección no será más probable que el no cambio.

Cuantitativamente (comprobado), el resultado llega a ser muy convincente. Después de hallada la explicación de la "regresión a la media", no hay conducta melódica residual que pueda atribuirse a un hipotético principio de llenado de vacío. Aunque las pesquisas sobre aspectos periféricos del problema continúan, aparece ahora que tal llenado es un concepto musical sin asidero en la realidad en una grande y diversa muestra de música real notada (musicalmente).

\footnotetext{
11. Los estadísticos han escrito extensamente sobre el fenómeno de la regresión a la media. Desafortunadamente, parecería ser un concepto difícil de captar para algunos humanos. Aún el laureado premio Nobel W. F. Sharpe, incorrectamente tomó la expresión como un nuevo fenómeno económico (ver, por ejemplo, “los puntajes de prueba estadística regresan hacia la media?" de Gary Smith). Como suele suceder con descubrimientos significativos, una búsqueda cuidadosa de fuentes bibliográficas y hemerográficas encuentra, a veces, que el mismo descubrimiento fué hecho décadas antes por otro académico. En un estudio de 1924, Henry Watt sugería que el “llenado de vacío” en música puede ser atribuido a la regresión hacia la media. Dado el bajo nivel de conocimientos numérico-estadísticos entre los académicos musicales, puede predecirse que tomará, a la mayoría de ellos, otros 70 años entender lo que ya se ha demostrado en cuanto al "llenado de vacío".
} 


\section{Las promesas de los métodos cuantitativos.}

Como ya se ha argumentado, los métodos cuantitativos son importantes por la misma razón por la que la notación musical puede serlo: como ésta, aquéllos nos permiten observar patrones organizativos difíciles o imposibles de descifrar de otro modo. Para el neoempirista, el interés en los métodos cuantitativos nada tiene que ver con la ciencia (exacta o natural) y sí todo que ver con llegar a ser un académico más conspicuo (y preparado).

Finalmente, consideremos el valor de la metodología cuantitativa en resolver cómo se hacen afirmaciones en humanidades. Para quien observa desde afuera del campo, pareciera, a menudo, que la esencia del debate académico es que un estudioso cree que $\mathrm{X}$ es verdadero mientras que otro lo cree falso. Pero casi todos los desacuerdos se relacionan con sombras sutiles de certidumbre. Considerémos, por ejemplo, los siguientes asertos:

1. Tchaikovsky, casi seguramente, no incurrió en suicidio.

2. Tchaikovsky, muy probablemente, no incurrió en suicidio.

3. Tchaikovsky, probablemente, no incurrió en suicidio.

4. Tchaikovsky, quizás, no incurrió en suicidio.

5. Tchaikovsky podría haber o nó incurrido en suicidio.

6. Tchaikovsky, probablemente, cometió suicidio.

7. Tchaikovsky, probablemente, no cometió suicidio.

8. Tchaikovsky, muy probablemente, cometió suicidio.

9. Tchaikovsky, casi seguramente, cometió suicidio.

La mayoría de los estudiosos del compositor sospecha que no se suicidó, pero no están de acuerdo en la fuerza de las evidencias y, por tanto, tampoco en cómo un académico debería expresar esta idea. Muchos aceptarían (2), (3) o (4) pero (1) sería pensado excesivo. Mientras que un académico dado puede favorecer (2) en un artículo revisado por pares, la ira de sus colegas podría ser provocada si un libro suyo afirma (1). Ésas son las precisiones propias de la academia.

Los investigadores familiarizados con la metodología cuantitativa reconocerán inmediatamente que el desacuerdo asciende a incertidumbre acerca del valor de $\mathrm{p}$ (antes descrito), es decir, la probabilidad de cometer un error falso-positivo. En la investigación empírica, el potencial de engaño al reportar esta idea sería soslayado por el simple reporte del nivel estadístico de confianza.

Los métodos cuantitativos proveen poco beneficio cuando la cantidad de datos es tan minúscula como la que rodea la muerte de Tchaikovsky. Pero hay innumerables asuntos musicales acerca de los cuales los métodos cuantitativos son indispensables y poderosos. Los directores pueden enorgullecerse de sus oídos de oro pero las economistas Claudia Goldin y Cecilia Rouse han juntado los números concretos que comparan audiciones abiertas y a ciegas: los resultados son consistentes con una discriminación rampante y sistemática contra los miembros orquestales femeninos (Goldin y Rouse, 2000). 
Para calificar los escritos de otro académico, ¿cómo podemos saber si el escritor es culpable de usar retórica exagerada? De la misma manera que el investigador de Tchaikovsky al comentar sobre su muerte, los académicos pueden, con razón, preguntarse si la afirmación de, digámos, un académico feminista, está siendo exagerada o subafirmada. Pero, para quienes entienden los métodos cuantitativos, los números pueden ser mucho más apremiantes, afirmativa o negativamente, que cualquier retórica florida.

\section{EL USO DE LA METODOLOGÍA CORRECTA.}

Ya debería estar claro que debemos mirar las metodologías como herramientas (medios) para conducir investigación y nó como creencias filosóficas. Como toda herramienta, una metodología dada está indicada para ciertas clases de búsqueda, pero no para otras. En la prosecución de un proyecto investigativo, los académicos bien avisados harán inventario de las condiciones de su área de búsqueda y escogerán el acercamiento metodológico que mejor sirva las metas de la investigación, a la luz de las oportunidades y los peligros inherentes a las tareas específicas. La metodología más apropiada puede cambiarse, según la tarea específica o las hipótesis que se estén considerando.

El impedimento principal para la selección cuidadosa de los métodos más apropiados es la inercia metodológica que puede encontrarse en el desarrollo de la mayoría de las disciplinas. Se suele enseñar a los investigadores una única metodología y se espera que ella sea aplicable, en mayor o menor grado, virtualmente a todas las tareas investigativas. En palabras de Abraham Maslow, a la persona que blande un martillo, todo el mundo siempre parecerá un clavo.

Aún cuando hay investigadores que tienden a utilizar métodos apropiados para su campo, somos a veces insensibles a cambios sutiles en un área, que deberían llevarnos a revisitar y revisar nuestras estrategias y propósitos metodológicos. En las secciones que faltan, nos referiremos a algunos de los malentendidos y fallas que acaecen por equivocarse en reconocer, ya sea (1) las diferencias específicas del campo o (2) las condiciones cambiantes dentro de un área del conocimiento.

\section{Entender los métodos en las humanidades.}

Los científicos expresan a veces su desencanto ante los bajos niveles de evidencia que parecen comunes en las disciplinas humanísticas, en formas de ver que no deberían tener lugar por dos razones. Primera: muchas actividades humanísticas enfrentan hipótesis de bajo riesgo, en el sentido de que la comisión de un error falso - positivo en cuanto a ellas tendría modestas repercusiones. Segunda: simplemente, no puede esperarse que las disciplinas pobres en datos satisfagan altos estándares de evidencia.

Enfrentados a volúmenes de datos frecuentemente pobres, la mayoría de los científicos jamás consideraría emprender el tipo de proyectos de investigación que se halla en las humanidades y estaría tentada a concluir que ningún reclamo de nuevo conocimiento debería hacerse. Pero esto equivaldría a presumir que los errores falso - negativos no tienen repercusiones morales. Podría aceptarse que 'las lecciones de 
la historia’ están pobremente sustentadas y son no confiables, pero ¿cuáles son las consecuencias de concluir que es imposible aprender de la historia? Los historiadores tienen razón, podemos creer, en tratar de buscar sentido en evidencia histórica incompleta y ecléctica, ya que fallar en aprender de ese material podría condenarnos a repetir errores pasados.

Por eso, no debería sorprendernos que los investigadores de campos pobres en datos estén típicamente orientados al escepticismo conserva - teorías más que al escepticismo descarta - teorías, pues cuando los datos son escasos, seguir el último camino significaría concluir que no es posible conclusión alguna, que no es formulable ni sostenible teoría alguna y habría que abandonar esa disciplina.

Hay circunstancias, empero, en que el desencanto expresado por los científicos en cuanto a la evidencia en las humanidades es acertado y apropiado. En especial, esta crítica es fundada (1) cuando los riesgos de cometer un error falso-positivo tienen repercusiones morales (o estéticas) significativas y (2) cuando el campo no es, o no necesita ser, pobre en datos. Ambas circunstancias surgen con alguna regularidad en las disciplinas humanísticas tradicionales. Más aún, la presencia de una u otra circunstancia haría necesario buscar cambios significativos en la metodología. Un ejemplo instructivo histórico puede hallarse en la separación de las ciencias sociales y las humanidades.

\section{Separación de las ciencias sociales y las humanidades.}

Las humanidades tratan el comportamiento humano, la sociedad civil y la cultura. Los humanistas académicos hacen afirmaciones sobre la naturaleza humana, la conducta moral o inmoral, y dan consejos acerca de las instituciones políticas, educativas y culturales. Los puntos de vista académicos concernientes a estas áreas de los asuntos humanos pueden, y frecuentemente así ocurre, tener influjo importante. A fines del siglo XIX, las ciencias sociales comenzaron a tomar distancia de los criterios de abordaje en las humanidades tradicionales, precisamente porque los académicos más ponderados reconocieron la necesidad de estándares de evidencia más altos en la sustentación de los reclamos de nuevo conocimiento, especialmente aquéllos que podrían influir en las actitudes y políticas públicas.

Al reconocer los riesgos de cometer errores falso - positivos, los científicos sociales tuvieron razón en acometer cambios en sus métodos de búsqueda. El darse cuenta de que las ciencias sociales podían aumentar claramente sus volúmenes de evidencia para informar las teorizaciones de sus investigadores, contribuyó también a esa revolución.

Por décadas, empero, un cierto número de académicos humanistas han criticado la psicología y la sociología modernas por adoptar métodos más comúnmente asociados con las ciencias físicas. No obstante, tales críticas se han basado en la falsa asunción de que las disciplinas se definen, nó sólo por sus objetos de estudio, sino por sus métodos. Como ya vimos, los métodos dependen, nó de los asuntos tratados, sino de los riesgos de las hipótesis adoptadas, de la accesibilidad de datos pertinentes, de la habilidad de los investigadores para la observación de los efectos de las manipulaciones a priori y 
por la oportunidad de recoger evidencia independiente de la original utilizada para formular teoría o interpretación.

Es erróneo, creo, considerar las metodologías como lealtades filosóficas; no se trata de si los métodos "científicos" prevalecen sobre los "interpretativos", hermenéuticos", "fenomenológicos" u otros cualesquiera tradicionales de las humanidades o viceversa, sino de si los investigadores usan la mejor metodología (o "canasta" de ellas) para la tarea emprendida.

Para muchos académicos, pareciera que, en el decurso del siglo $\mathrm{XX}$, las humanidades hubiesen "perdido" un número de disciplinas, incluida la lingüística, la arqueología, la psicología y, en menor grado, la antropología y la sociología. No estoy de acuerdo. Los objetos de estas disciplinas cambiaron poco durante el siglo XIX. Los lingüistas aún se interesan por los orígenes, estructuras y adquisición de los lenguajes humanos; los arqueólogos, por cómo los artefactos nos informan de pasadas civilizaciones; los psicólogos, por los pensamientos y motivaciones humanas; los sociólogos y antropólogos, por la naturaleza de la interacción humana y de la cultura; en cada disciplina, los seres y las vidas humanas permanecen centrales. Lo que ha cambiado para ellas es, primordialmente, el volumen de evidencia accesible $y$, consiguientemente, las posibilidades de enfrentar cuestiones más refinadas usando los métodos que mejor puedan explotar los nuevos recursos en datos.

La perspectiva de obtener acceso a mayor cantidad evidencia o información básica no es, simplemente, una oportunidad que puede ser tomada o dejada de lado, según se quiera. Cuando nuevos datos pertinentes sean accesibles, será moralmente reprensible no usarlos, ya que ello aumentaría la posibilidad de no cometer errores, tanto del tipo falso - positivo como falso - negativo. En suma, los datos empíricos merecen nuestra atención, precisamente por la misma razón por la que poca cantidad de ellos obliga al historiador a realizar sus mejores esfuerzos interpretativos: fallar en tratar de aprender de la información accesible es permitir y reforzar la ignorancia.

\section{LA FÍSICA DE PARTÍCULAS: REPERCUSIONES DE LA DISMINUCIÓN DE DATOS.}

Aunque hay circunstancias que abren las puertas al flujo de datos, hay otras que los cierran, a su vez. Debemos admitir que no es común que una disciplina experimente una reducción en el volumen de datos, pero ocurre. El campo de la física de partículas es, podemos afirmarlo, un tal campo. El éxito mismo de la física subatómica ha empujado las fronteras del conocimiento a rincones más y más esotéricos de la realidad. Los físicos de partículas no pueden realizar experimentos sin acceso a maquinaria enormemente costosa. Después de gastar cerca de dos mil millones de dólares en la preparación de la construcción del super colisionador super conductor (SSC), en 1993 el gobierno estadounidense decidió abandonar el proyecto por muy costoso. Aunque los investigadores pueden continuar recogiendo datos, los físicos tienen pocas oportunidades de que ellos sean pertinentes para (comprobar) los últimos asuntos y modelos teóricos.

Aún si el SSC hubiera sido construido, su utilidad hubiese sido limitada. Las teorías más desarrolladas de la realidad física exceden nuestras capacidades de comprobación; 
por ejemplo, para poner a prueba hipótesis que surgen de la teoría de las supercuerdas, se ha estimado que un acelerador de partículas necesitaría tener una circunferencia de mil años luz (Horgan, 1996, pág. 62). Con la creciente escasez de datos pertinentes, la física subatómica se está transformando en una empresa puramente teórica. De hecho, la física cuántica ha atraído numerosas interpretaciones en competencia, con poca esperanza de que alguna vez se realicen pruebas que pudieran descartar las incorrectas. El premiado Nobel Sheldon Glashow expresaba el descontento en su campo de esta manera: "la contemplación de las supercuerdas podría evolucionar hasta llegar a ser una actividad...conducida en escuelas de divinidad por equivalentes futuros de teólogos medievales." (Glashow y Ginsparq, 1986, pág. 7).

Tal alusión a la teología es una mofa, pero los físicos de partículas podrían necesitar acostumbrarse a la inevitable transformación metodológica que espera a su disciplina. Los humanistas pueden ser perdonados por sus lágrimas de cocodrilo: por siglos, los historiadores han tenido que luchar por hallar sentido a fragmentos de manuscritos que saben que no pueden completarse. Con datos finitos (escasos), la interpretación es la única actividad académica que queda; más aún, la empresa interpretativa, hermenéutica, conserva su valor.

\section{LA MUSICOLOGÍA: REPERCUSIONES DE LA CRECIENTE DISPONIBILIDAD DE DATOS.}

Mientras la física subatómica se mueve a un período de datos escasos, la situación contraria parece que sucede a la música. Como ya se anotó, las innovaciones técnicas y organizativas pueden transformar campos pobres en datos en ricos en ellos. Por los últimos 25 años, esas innovaciones han surgido en muchas áreas del estudio musical, tras huellas como las de la Lingüística, la educación y la antropología. Los académicos contemporáneos de la música tienen acceso a recursos computacionales y a bases de datos, herramientas comprehensivas de referencia, métodos de adquisición de datos de alta calidad, técnicas sofisticadas de modelación y otras innovaciones que hacen mucho más fácil recoger, analizar e interpretar evidencias y artefactos musicalmente pertinentes. Apenas hay área alguna de la música que no pueda beneficiarse de los recursos crecientes y de la consiguiente posibilidad de adoptar estándares de evidencia más rigurosos que incluye áreas como estudios de manuscritos, poética, historia, iconografía, análisis, ejecución, pedagogía, recepción, estética y crítica, fenomenología, teoría social y crítica, estudios culturales, política cultural, medios y etnología. No todas las áreas de la academia musical han sido o serán beneficiadas por los recursos en expansión ni la musicología especulativa y creativa perderán enteramente su valor, empero.

El panorama cambiante de la musicología hacia enfoques más empíricos no implica el reemplazo del espíritu de las humanidades por un ethos científico antitético; es, fundamentalmente, una respuesta a un entendimiento epistemológico más claro del papel de la metodología. Las condiciones cambiantes, sencillamente, nos permiten ser mejores investigadores de la música, abrazar estándares más altos de evidencia y llegar a estar más agudamente conscientes de las repercusiones morales y estéticas de nuestras conclusiones, incluidas las de que algo no es cognoscible o de 
que un fenómeno no debería ser investigado. Nuestras críticas más fuertes podrían ser dirigidas a quienes insisten en el discurso especulativo cuando hay recursos al alcance para comprobar la validez de esas conclusiones.

\section{EVALUACIÓN DE INFLUENCIA EN EL DISCURSO DE LAS HUMANIDADES.}

La discusión anterior se ha referido sólo de paso al asunto de la evaluación de las repercusiones morales y estéticas de las afirmaciones de creación de nuevo conocimiento. Pocos aspectos del discurso humanístico comportan mayor necesidad de discusión. Es necesario que los académicos humanistas no sean inocentes acerca del influjo y la importancia de las ideas. Es peligroso suponer que, en comparación con las tecnologías (con su considerable potencial de daño - mischief), las ideas son, de algún modo, frágiles e inocentes. Karl Marx nunca cesó de denigrar de lo que llamó "meras ideas"; decía que los filósofos se habían contentado con, simplemente, hablar acerca del mundo con poco interés en cambiarlo. Desafortunadamente no vivió para ver la cruel ironía de sus palabras. Ningún otro individuo ha producido un efecto moral sobre las vidas humanas en el siglo XX como Marx, aunque era un filósofo quintaesencialmente encerrado. Antes de soltar una idea por el mundo, ésta debería estar sujeta a evaluación de influencia ambiental de la misma manera como la aplicamos a las carreteras y a los químicos. Ideas no totalmente cocidas han sido tan perniciosas y peligrosas como alguna innovación tecnológica podría serlo y quizás más. Los humanistas no deberían subestimar su poder para cambiar el mundo y, al tiempo, su culpabilidad cuando se cometen errores.

\section{LA METODOLOGÍA COMO GUÍA ANTI-TRAMPAS.}

Posiblemente, el malentendido más dañino sobre la metodología sea el de que los métodos académicos deparan algoritmos para adelantar investigación. De acuerdo con este punto de vista, la metodología es una especie de receta que siguen los buscadores de conocimiento en el curso de sus estudios, con lo que la función de los epistemólogos se presume como cocer algoritmos metodológicos cada vez más refinados y detallados. Puede hallarse una relación entre esos falsos conceptos y los que se refieren a los procedimientos en las pruebas matemáticas pues, a pesar de que los procedimientos deductivos utilizados por los matemáticos estén, sin duda, atados a reglas, la investigación matemática misma es una empresa mucho más compleja.

Tal como ya se hizo notar en la primera parte, la idea de "la metodología como algoritmo" se ha sometido a ataques sostenidos y devastadores en el siglo XX (Agassi, 1975; Feyerabend, 1975; Gellner, 1974; Kuhn, 1962; Laudan, 1977; Popper, 1934; Polanyi, 1962; Quine, 1953 y otros). Muchos de esos ataques han provenido de autores cuya motivación era defender la racionalidad de la ciencia; la conclusión preponderante de esas críticas es que ningún conjunto de reglas puede garantizar el avance del conocimiento. Más aún, según vimos, aún la regla metodológica más flexible jamás propuesta, el "todo vale" de Feyerabend, falla en haber surgido por observación. 
De los varios esfuerzos por reformular nuestra concepción de la metodología académica, uno de los mejor informados y más detallados ha sido el ofrecido por el epistemólogo Jaqdish Hattiangadi. En su "Metodología sin reglas metodológicas", arguye que, como las teorías científicas, las metodológicas son actividades de descubrimiento, para las cuales no hay reglas fijas. El investigador que sigue cerradamente una metodología fija terminará por incurrir en un error oneroso.

Hattiangadi mira los campos académicos como tradiciones de debate que desarrollan problemas y criterios al tiempo en que avanzan; aunque la racionalidad está ligada a la tradición, no está constreñida sólo por lo que creemos. Lo que descubren los metodólogos son líneas guías o heurística.

En nuestra larga carrera de errores, los académicos hemos llegado a identificar "trampas" en el camino de la intelección, aprendido a reconocer y evitar una multitud de falacias lógicas y retóricas que incluyen los argumentos ad hominem, las apelaciones a la autoridad (ipse dixit), la falacia del naturalista, la positivista, la reificación o hipostatización y una hueste de otras trampas en la explicación histórica (Elster, 1989; Fischer, 1970; Roberts, 1996). Semejantemente, los científicos contemporáneos han identificado otros innumerables peligros adicionales, entre los cuales están el razonamiento regresivo, el sesgo del experimentador, los efectos de techo, la característica demandante, el problema de las pruebas múltiples, el problema de la tercera variable, los efectos de cohorte (Schaie, 1986) y el problema de la reactividad (Webb, Campbell, Schwartz, Sechrest y Grove, 1981). Estos y otros problemas están todos bien documentados y, en muchos casos, reglas efectivas se han diseñado para reconocer, evitar o minimizar sus efectos corrosivos en la investigación académica.

Los investigadores son libres para escoger o desarrollar su propia metodología, ya deductiva, empírica, fenomenológica u otra cualquiera; pero la persecución del conocimiento se sirve mejor cuando ellos aprenden de las diferentes tradiciones debatientes en existencia. Aunque no hay un mapa detallado de caminos para adelantar investigación, hay esbozos de trampas bien documentadas que otros buscadores han hallado y es importante estar alerta ante estos peligros conocidos y mantenerse al tanto de los descubrimientos en metodología, pues ésta no es, simplemente, una especialidad abstracta de la filosofía, sino una interconsulta transdisciplinaria utilitaria que ofrece asistencia práctica diaria accesible a todos los investigadores.

En esto, lamentablemente, el postmodernismo ha hecho un flaco servicio a las humanidades. Muchos, por lo demás, pensadores juiciosos se han convencido de que no hay posibilidad de rigor y de que la metodología es una ilusión peligrosa. Como resultado, una generación completa de estudiantes de humanidades y artes han sido privados de educación práctica adecuada en la metodología. Al escéptico postmodernista, podría uno responder con un escepticismo inverso: ¿Y qué pasa si hubiera verdades? ¿Y qué si algunas de ellas fueran cognoscibles? ¿Y qué si unas interpretaciones fueran mejores que otras? ¿Y qué si falláramos en aprender de la evidencia que está a nuestro alcance? 


\section{CONCLUSIÓN}

Como conclusión, los argumentos básicos aquí presentados pueden ser reconstruidos y resumidos como sigue:

1. Los postmodernistas tienen razón en hacer notar que las afirmaciones presentadas como nuevo conocimiento no tienen lugar en un vacío moral. Teorías, hipótesis, interpretaciones y opiniones comportan repercusiones morales y estéticas; pero escoger evadir la producción de conocimiento es también un acto con consecuencias morales.

2. Quien desee llegar a algún descubrimiento acerca del mundo, no tiene otro opción que navegar por la senda procelosa entre los errores falso - positivos y falso negativos y eso incluye reclamos como "no sé" y "no podemos saber". Estos asertos negativos no son más seguros, epistemológicamente hablando, que los positivos "yo sé" o "en principio, podemos saber".

3. El "problema de la inducción” es indeleble y ubicuo: ninguna cantidad de observación puede establecer la verdad de una proposición y el problema se aplica, no sólo al empirismo, sino también a las críticas que se le hacen, por parte de escritores anti-fundacionalistas como Feyerabend, pues ninguna cantidad de observación sobre la Historia de la Ciencia puede certificar la afirmación de que la empresa científica sea irracional o arracional.

4. A pesar del problema de la inducción, la observación permanece como indispensable para el conocimiento en maneras que no entendemos (completamente). Nuestra maquinaria biológica misma ha evolucionado para facilitar la adquisición de conocimiento acerca del mundo (que nos rodea) y podemos demostrar que las observaciones son consistentes con unas teorías y nó con otras, aún si no pudiéramos demostrar que una teoría es mejor que la otra.

5. Los campos de estudio difieren en cuanto al volumen y calidad de evidencia (datos) disponible, usables para sostener o favorecer diferentes asertos, puntos de vista, interpretaciones o teorías.

6. Cuando los datos son inaccesibles o inexistentes, el campo es susceptible de ser juzgado (candidato a) incurso en la falacia del positivista: la ausencia de evidencia podría interpretarse como evidencia de ausencia.

7. Los campos pobres en datos no pueden sostener investigaciones que tengan como una meta el minimizar la ocurrencia de afirmaciones falso - positivas. Por tanto, el escéptico descarta - teorías evita asumir investigación alguna en tales campos y concluye que no pueden sacarse conclusiones de los datos accesibles.

8. Otros académicos reconocerán las graves repercusiones morales de fallar en tratar de aprender de pequeñas cantidades de evidencia en un campo dado y éste atraerá sólo a escépticos conserva - teorías, cuyo objetivo es minimizar la ocurrencia de afirmaciones falso - negativas.

9. Cuando el volumen de datos es pequeño, los escépticos falso - negativos muestran consistencia cuando sostienen hipótesis o interpretaciones múltiples alternativas. 
El pluralismo es, entonces, preferible a la parsimonia y las conclusiones son, más bien, abiertas que cerradas.

10. Desgraciadamente, algunos académicos que trabajan en campos pobres en datos, incurrirán, típicamente, en errores falso - positivos y promulgarán ideas sin mérito.

11. Los campos ricos en datos depararán gran oportunidad de poner a prueba una hipótesis y criterios más rigurosos permitirán la comprobación minimizante de reclamos falso - positivos. Como resultado, hipótesis conflingentes pueden ser rechazadas con alguna seguridad. Se prefiere entonces la parsimonia al pluralismo y los investigadores buscan explicaciones cerradas.

12. Los datos pueden caracterizarse también como retrospectivos o prospectivos. Los retrospectivos (solos) conllevan dos problemas metodológicos: a) la posible ocurrencia del académico "cuenta - cuentos", adepto a la formulación de teorías que dan cuenta de cualquier conjunto de datos existente, en las que los datos retrospectivos se utilizan, tanto para llegar a la formulación de la teoría como a la provisión de evidencia favorable; b) la imposibilidad de inferir relaciones de causa - efecto.

13. En cambio, los datos prospectivos hacen posible retar teorías o explicaciones por la comparación de predicciones con respecto a nuevos datos surgentes. Pocas demostraciones de la posibilidad de conocimiento compelen más que la predicción de observaciones, por otra parte, improbables.

14. Se pueden distinguir dos tipos de datos prospectivos: los que pueden ser influidos por el investigador y los que nó. Los primeros permiten manipular las condiciones iniciales y, por tanto, inferir posibles causalidades. Los segundos, nó.

15. El que uno mantenga una actitud escéptica conserva - teorías o descarta - teorías, debería depender de las repercusiones éticas o estéticas de incurrir en errores falso - positivos o falso - negativos, de acuerdo con el reclamo, hipótesis o interpretación en cuestión.

16. Los académicos en todos los campos de estudio deberían mantener flexibilidad en la escogencia de la metodología que mejor convenga a la tarea que va a emprenderse. Esa escogencia debería ser informada, tanto por las repercusiones éticas y estéticas de la incursión en los dos tipos de errores, cuanto por las circunstancias particulares del campo mismo.

17. En casi todos los casos, la investigabilidad es favorecida por la accesibilidad a evidencia adicional. Como (ocurre con) los juristas acusadores (de la fiscalía), los académicos tienen la obligación moral de buscar otras fuentes de evidencia (datos), tantas como puedan obtenerse. La magnitud de esta obligación es proporcional a las repercusiones morales de la hipótesis.

18. Las pruebas estadísticas de inferencia pueden ser usadas con igual eficacia por los escépticos conserva - teorías como por los descarta - teorías. Los primeros han subutilizado las pruebas estadísticas.

19. las condiciones materiales y estructurales de cualquier campo investigativo son susceptibles de cambiar. Una causa común de cambio es el aumento o la disminución de datos pertinentes accesibles. Las condiciones cambiantes 
demandan, con frecuencia, cambios en las metodologías investigativas con el fin de minimizar los riesgos morales.

20. La escogencia de una metodología apropiada es (por tanto) una decisión moral. Cuando un académico no está al tanto de las opciones metodológicas, su selección de una metodología será moralmente desinformada.

21. Las metodologías deben mirarse como herramientas académicas; los investigadores deberían oponerse a la tendencia a mantener metodologías como si fueran sistemas universales de fe.

22. No hay algoritmo metodológico que asegure el avance del conocimiento. La metodología consiste, primordialmente, en un conjunto de índices que previene a los académicos sobre trampas o peligros previamente encontrados y se extiende y refina como cualquier otra teoría.

En este escrito, me he aplicado a reactivar el punto de vista de que las humanidades se distinguen de las ciencias, principalmente, por su objeto de estudio y, secundariamente, por una tendencia filosófica hacia concepciones más humanísticas que mecanicistas del mundo. Aún más importante, he argumentado contra la idea de que las ciencias y las humanidades se distinguen necesariamente por sus hábitos metodológicos. Es cierto que las disciplinas humanísticas tienden, generalmente, a adoptar un escepticismo falso - negativo, a ser de orientación histórica, a preferir el pluralismo sobre la parsimonia y a preferir relatos abiertos más que explicaciones cerradas. No obstante, he hecho notar que estas tendencias metodológicas surgen, principalmente, de las estructuras y circunstancias materiales que rodean los campos particulares de estudio involucrados. En particular, muchas disciplinas humanísticas (pero nó todas) son comparativamente pobres en datos, trabajan con hipótesis de bajo riesgo y no pueden realizar experimentos formales. Las disciplinas pobres en datos repelen al escéptico falso - positivo porque ellas conllevan un ambiente donde el escepticismo falso - positivo no da resultados.

Mi afirmación de que las diferencias metodológicas surgen, principalmente, de las condiciones investigativas concretas de las disciplinas, no debería evocar sorpresa alguna; los filósofos del conocimiento concuerdan en que lo que podríamos llamar "racionalidad" en sentido lato no es disciplinariamente específico. Lo que sea bueno para el "ganso" epistemológico debería ser bueno para la "gansa" epistemológica también.

Los diversos campos de estudio tienen necesidades metodológicas específicas por disciplina. Un ejemplo: los estudios de manuscritos han desarrollado métodos analíticos basados en marcas de agua, líneas encadenadas, patrones de encuadernación y otros. Empero, hay también patrones subyacentes de cómo las diferentes disciplinas abordan la prosecución de sus metas y hay algunos principios unificadores en lo investigativo. Mientras las humanidades y las ciencias pueden correctamente diferenciarse en sus conceptos filosóficos alrededor de la naturaleza del mundo, sin embargo comparten profundas coincidencias en métodos. Todas las áreas de estudio pueden beneficiarse ampliamente con la gran variedad de métodos investigativos al alcance y con los muchos índices contra las trampas metodológicas. 


\section{El nuevo empirismo.}

Investigar comienza por preguntarse acerca del mundo. En el caso de la música, hay multitud de cuestiones válidas que pueden ser propuestas. En muchos casos, hay repercusiones morales negativas cuando se escoge no investigar algún asunto. Ofrecer la excusa de que "nunca podríamos estar seguros sobre la respuesta a esa pregunta" es más vacío que noble, pues puede aplicarse a todas las cuestiones empíricas. Las buenas preguntas verdaderamente retan a los académicos a hacer su mejor labor en la recolección de evidencia que pueda ayudar a producir respuestas informadas, así sean limitadas y provisionales.

En la década pasada, números crecientes de estudiosos musicales han sido atraídos por las oportunidades ofrecidas por los métodos empíricos. El nuevo empirismo reconoce que la observación formal puede, sin duda, conducir a hallazgos genuinos acerca de la música y la musicalidad. Tal como ya se anotó, lo que el nuevo empirismo comparte con el postmodernismo es la convicción de que las pesquisas académicas ocurren en un dominio moral y, por tanto, la metodología debería guiarse por consideraciones morales.

Claro que algunos objetos investigativos están aquejados por la escasez de evidencia pertinente; pero hay modos razonables de tratar de descifrar la semejanza (aproximación, parecido o cercanía), aún si jamás podemos adivinar la verdad. Muchos asuntos nos permiten recoger cantidades de datos pertinentes y usar métodos estadísticos de inferencia que nos dejen minimizar, tanto los errores falso - positivos como los falso - negativos.

El nuevo empirismo tiene tres quejas sobre las ciencias: Los científicos yerran en menospreciar o ignorar campos que son pobres en datos y áreas en las que la experimentación es imposible; yerran también al asumir el 0.05 de nivel de confianza como una suerte de estándar inmutable de inferencia y, para campos con limitación severa de datos, deberían aceptarse niveles entre 0.1 y 0.2, si los riesgos asociados con la incursión en errores falso - positivos son bajos; yerran, asimismo, cuando asumen siempre, como meta de la investigación, la minimización de errores falso - positivos.

Además, el nuevo empirismo tiene quejas también contra nuestros colegas humanistas: el empirismo no es una palabra sucia; hay muchos asuntos musicales, históricos, estéticos, culturales, analíticos, teóricos, ejecutivo - interpretativos, poéticos, psicológicos (recepción y audición) y otros, que pueden ser abordados útilmente con métodos de inferencia estadística. Al contrario de lo popularmente pensado, la estadística no prueba cualquier punto de vista.

Podría parecer al músico académico tradicional que, en todo el mundo, la ciencia ejerce fuerte influencia sobre la musicología. Sin embargo, la surgencia del empirismo no se debe, en tal caso, a la ciencia. Nace desde dentro de la música académica misma y halla su motivación en el deseo de aprender tanto cuanto sea posible de la información que nos sea accesible, incluida aquélla adicional que pudiera recolectarse sin mayor esfuerzo. La búsqueda de evidencia es una obligación moral. De nuevo, la analogía con la jurisprudencia es convincente: si un fiscal tiene la oportunidad de ganar acceso a un 
cúmulo de nuevos datos, sería éticamente reprensible no examinar ese material que permita establecer más firmemente la culpabilidad o inocencia de alguien.

Perseguir el rigor no es una especie de fetiche metodológico; es, simplemente, el intento de evitar trampas bien documentadas en cuanto a la investigación. No deberíamos ser cínicos con aquellos académicos que aspiran a lograr lo mejor.

A la luz de las observaciones previas, ya debería ser obvio que debemos creer que científicos y humanistas deberían ser educados con la mira de acceder a un repertorio más amplio de metodologías investigativas. Particularmente, los humanistas deberían aprender lo básico de la inferencia estadística y los científicos (de las ciencias fácticas) deberían exponerse a aproximaciones fenomenológicas y deconstructivistas.

Finalmente, los filósofos de la moral y la ética deberían interesarse más en la ética epistemológica. Los reclamos de producción de nuevo conocimiento tienen consecuencias y es importante que los académicos reconozcan las repercusiones éticas y estéticas de sus puntos de vista, incluido aquél de que algo es inconocible. Más investigación de los riesgos es necesaria para ayudar a los investigadores a reconocer cuándo adoptar una política conserva - teorías o una descarta - teorías.

\section{Referencias}

Agassi, Joseph. (1975). Science in Flux. Dordrecht, Holland: D. Reidel Publishing Co. Anderson, Philip. (1972). More is different. Science, Aug. 4, 1972, pp.393-

Ayer, Alfred J. (1936). Language, Truth and Logic. London: Victor Gollantz.

Belsey, Catherine. (1993). "Towards Cultural History," en: A Postmodern Reader, J. Natoli \& L. Hutcheon (eds.) New York: SUNY Press, pp. 561, 555-556 [sic]. La cita es de la pág. 561.

Cozby, Paul C. (1989). Method in Behavioral Research. Mountain View, CA: Mayfield Publishing Co., 4th edition.

Cook, Nicholas. (1990). Music, Imagination, and Culture. Oxford: Clarendon Press.

Duhem, Pierre. (1905). La Théorie Physique: son Objet, sa structure. Paris: Marcel Rivière; 2eme. edition, 1914. Translated by P.P. Wiener as: The Aim and Structure of Physical Theory, Princeton: Princeton University Press, 1954; reimpresa en New York: Atheneum, 1962, 1977.

Elster, John. (1989). Nuts and Bolts for the Social Sciences. Cambridge: Cambridge University Press.

Feyerabend, Paul. (1975). Against Method: Outline of an Anarchistic Theory of Knowledge. London: Verso Editions 7. 
Fischer, David H. (1970). Historians' Fallacies: Towards a Logic of Historical Thought. New York: Harper Collins.

Fitt, Mary. (1959). Diels' Fragmente der Vorsokratiker. Translated by Kathleen Freeman as Ancilla to The pre-Socratic philosophers: A complete translation. Cambridge: Harvard University Press, 1983; 5th edition.

Foucault, Michel. (1970). The Order of Things: An Archaeology of the Human Sciences. New York: Pantheon, 1970.

Foucault, Michel. (1977). Discipline and Punish: The Birth of the Prison. New York: Vintage/Random House.

Gell-Mann, Murray. (1994). The Quark and the Jaguar. New York: W.H. Freeman.

Gellner, Ernest. (1974). Legitimation of Belief. Cambridge: Cambridge University Press.

Glashow, Sheldon \& Ginsparg, Paul. (1986). Desperately seeking superstrings. Physics Today, May 1986, p.7.

Gleick, James. (1987). Chaos: Making a New Science. New York: Penguin Books.

Goldin, Claudia \& Rouse, Cecilia. (2000). Orchestrating impartiality: The impact of 'blind' auditions on female musicians. American Economic Review, September 2000.

Goodman, Nelson. (1976/1981). Languages of Art; An Approach to a Theory of Symbols, Brighton, Sussex: Harvester Press.

Gould, S.J. (1978). Sociobiology: The art of storytelling. New Scientist, Vol. 80, pp. $530-$ 533.

Gould, S.J., \& Lewontin, R.C. (1979). The spandrels of San Marco and the Panglossian program: A critique of the adaptationist programme. Proceedings of the Royal Society of London, Vol. 250, pp. 281-288.

Hacking, Ian. (1995). Rewriting the Soul: Multiple Personality and the Sciences of Memory. Princeton, N.J.: Princeton University Press.

Hartsock, Nancy. (1990). "Foucault on power: A theory for women?" In: Linda Nicholson (ed.) Feminism/Postmodernism. New York: Routledge.

Hattiangadi, Jagdish N. (1983). A methodology without methodological rules. In: R. Cohen \& M. Wartofsky (eds.), Language, Logic, and Method. Dordrecht, Holland: D. Reidel Publishing Co., pp. 103-151.

von Hippel, Paul. (2000a). Redefining pitch proximity: Tessitura and mobility as constraints on melodic intervals. Music Perception, Vol. 17, No. 3, pp. 315-327.

von Hippel, Paul. (2000b). Questioning a melodic archetype: Do listeners use gap-fill to 
classify melodies? Music Perception, Vol. 18, No. 2, pp. 139-153.

von Hippel, Paul, \& Huron, David. (2000). Why do skips precede reversals? The effect of tessitura on melodic structure. Music Perception, Vol 18, NO. 1, pp. 59-85.

Horgan, John. (1996). The End of Science: Facing the limits of knowledge in the twilight of the scientific age. Reading, MA: Addison-Wesley Publisher.

Huron, David. (1996). The melodic arch in Western folksongs. Computing in Musicology, Vol. 10, pp. 3-23.

Kuhn, Thomas S. (1962/1970). The Structure of Scientific Revolutions. Chicago: University of Chicago Press.

Laudan, Larry. (1977). Progress and Its Problems: Towards a Theory of Scientific Growth. Berkeley: University of California Press.

Lewontin, R.C. (1991). Biology as Ideology. Concord, Ontario: Anansi Press and the Canadian Broadcasting Corporation.

Natoli, J. (1997). A Primer to Postmodernity. Oxford: Blackwell Publishers.

Nettl, Bruno. (1985). The Western Impact on World Music, New York: Schirmer Books. Neyman, J. and Pearson, E.S. (1928) On the use and interpretation of certain test criteria for purposes of statistical inference. Biometrika, A, Vol. 20, pp. 175-240,263-294.

Neyman, J. and Pearson, E.S. (1967). Joint Statistical Papers. Cambridge: Cambridge University Press.

Pagels, Heinz. (1988). The Dreams of Reason. New York: Simon and Schuster.

Pascal, Blaise. (1669). Pensées.

Plotkin, Henry. (1994). Darwin Machines and the Nature of Knowledge. Cambridge, MA: Harvard University Press.

Poggioli, Renato. (1962/1968). Teoria dell'arte d'avanguardia. Società editrice il Mulino. Translated by G. Fitzgerald as The Theory of the Avant-Garde. Cambridge, MA: Harvard University Press.

Polanyi, Michael. (1962). Personal Knowledge: Towards a Post-Critical Philosophy. Chicago: University of Chicago Press.

Popper, Karl. (1934/1959). Logik der Forschung. Vienna, 1934. Trans. as The Logic of Scientific Discovery. New York: Basic Books, 1959.

Rahn, John. (1983). A Theory for All Music: Problems and solutions in the analysis of nonWestern forms. Toronto: Toronto University Press.

Rahn, John. (1993). Differences. Perspectives of New Music, Vol. 31, No. 2, pp. 58-71. 
Quine, Willard Van. (1953). From a Logical Point of View. Cambridge, MA: Harvard University Press.

Roberts, Clayton. (1996). The Logic of Historical Explanation. University Park, PA: Pennsylvania State University Press.

Rosen, D.E. (1982). Telostean interrelationships, morphological function and evolutionary inference. American Zoologist, Vol. 22, pp. 261-273.

Seay, Albert. (1975). Music in the Medieval World. Englewood Cliffs, NJ: Prentice-Hall Inc.

Watt, Henry J. (1924). Functions of the size of interval in the songs of Schubert and of the Chippewa [i.e., Ojibway] and Teton Sioux [i.e., Lakota] Indians. British Journal of Psychology, Vol. 14, No. 4, pp. 370-386.

Webb, E.J., Campbell, D.T., Schwartz, R.D., Sechrest, R., and Grove, J.B. (1981). Nonreactive Measures in the Social Sciences. Boston: Houghton Mifflin, 2nd edition.

Este documento es accesible (en inglés original) en: http://dactyl.som.ohio-state.edu/ Music220/Bloch.lectures/3.Methodology.html 